\title{
Chile no va hoy a la fábrica: Protesta obrera y represión política en el verano de $1946 *$
}

\author{
Chile is not going to the factory today: Labor protest and political repression \\ in the summer of 1946
}

\begin{abstract}
Viviana Bravo Vargas**
Resumen: Este artículo reconstruye el intenso proceso de protesta obrera suscitado entre enero y febrero de 1946 y su impacto en el sistema político chileno. Siguiendo detenidamente la matanza de la Plaza Bulnes, el Paro Nacional del 30 de enero, y del 4 de febrero demostraremos que desde el fin de la Segunda Guerra Mundial se va configurando un nuevo ciclo represivo dirigido a neutralizar la disidencia, disciplinar al movimiento obrero e imponer la paz social en la relación capital-trabajo. Para este fin, además de referencias hemerográficas, nos apoyaremos en fuentes primarias escasamente trabajadas como informes de la Sección Sindical y Confidencial de la Policía de Investigaciones de Chile y del sumario por los hechos ocurridos en la Plaza Bulnes.
\end{abstract}

Palabras clave: Protesta obrera - huelga- Movimiento sindical- represión- Chile

\begin{abstract}
This article reconstructs the intense cycle of workers' protest of the Summer of 1946 and its impact on the Chilean political system. Focusing on the Bulnes Square massacre and the national work stoppages of January 30 and February 4, it argues that the government established new repressive mechanisms to neutralize dissent, discipline the labor movement, and impose social peace after the end of World War II. To achieve this purpose, the article relies on primary sources rarely analyzed before, such as reports of the Trade Union and Confidential Section of the Investigations Police of Chile and the court record of the Bulnes Square massacre, in addition to hemerographic sources.
\end{abstract}

Keywords: Labor protest, Strike, Trade union movement, Repression, Chile

Recibido: 2 febrero 2017

Aceptado: 3 abril 2017

\footnotetext{
Este artículo es parte del proyecto FONDECYT N³160354, titulado "Lucha de calles: voces y trayectorias de la protesta popular en Santiago de Chile, 1946-1969".

** Chilena, Docente, Universidad Academia de Humanismo Cristiano. Mail: vivianabravo@gmail.com
} 


\section{Introducción}

En enero de 1946 la Confederación de Trabajadores de Chile $(\mathrm{CTCH})$ convocó a una concentración pública en la Plaza Bulnes, ubicada frente al palacio de La Moneda, para protestar contra la supresión de la personalidad jurídica de dos sindicatos salitreros en huelga. A pesar de haber sido una manifestación autorizada, a la que asistieron hombres, mujeres y niños, esa tarde hubo más de 95 heridos, 51 de ellos a bala y 6 muertos, entre ellos, la joven obrera comunista Ramona Parra. ${ }^{1}$ Se trató de uno de los hechos represivos más cruentos que ha experimentado la ciudad de Santiago. No obstante, la investigación a cargo del fiscal militar Enrique Leyton Garavagno nunca esclareció lo ocurrido ni individualizó a los responsables. Los hechos se rodearon de una atmósfera muy confusa en la que colaboraron los medios de comunicación del gobierno: se habló de choque callejero, de enfrentamiento, de provocación. ${ }^{2}$

¿Cómo enmarcamos estos hechos de sangre dentro del proceso político chileno? ¿Fueron una excepción dentro de la supuesta paz social consensuada entre los gobiernos radicales y las organizaciones de trabajadores? Existe cierto consenso en señalar que con el régimen de Gabriel González Videla y su ruptura con los comunistas se abre un período represivo que se extiende hasta la administración de Carlos Ibáñez del Campo. A este período comprendido entre la década de 1948-1958 Tomás Moulian lo ha llamado Dominación represiva. Una periodización que desde nuestra perspectiva no clarifica la estrategia de dominación de los años previos y que debiésemos asumir dentro de lo que el mismo autor denomina Dominación defensiva (1942-1946) para dar cuenta de la posición relativamente favorable que alcanzaron los sectores populares y sus demandas dentro de la relación estatal. ${ }^{3}$ Por su parte, el politólogo Carlos Huneuus, aporta a la comprensión del período aclarando que si bien es innegable que con la promulgación de la Ley de Defensa Permanente de la Democracia -conocida como Ley Maldita- en septiembre de 1948, se agudizó y amplió a gran escala la persecución y represión a los militantes comunistas que afectaron al movimiento laboral en su conjunto, es importante considerar los diversos y

\footnotetext{
${ }^{1}$ Una reconstrucción de estos sucesos desde la perspectiva de la composición social de la protesta, en Alfonso Salgado, "La familia de Ramona Parra en la Plaza Bulnes: Una aproximación de género a la militancia política, la protesta social y la violencia estatal en el Chile del siglo". Revista www.izquierdas.cl, número 18, IDEA-USACH, Santiago de Chile, abril 2014, pp. 128-145. También en: Brian Loveman y Elizabeth Lira, Poder judicial y conflictos políticos (Chile:1925-1958), Santiago, LOM, 2014

${ }^{2}$ Ver por ej El Diario Ilustrado y El Mercurio los días 29, 30 y 31 de enero 1946

3 Tomás Moulian, Fracturas: de Pedro Aguirre Cerda a Salvador Allende (1938-1973), Santiago, LOM, 2006.
} 
recurrentes dispositivos jurídicos represivos que desde 1947 configuraron el Estado policial que caracterizó al gobierno de González Videla. ${ }^{4}$

Por nuestra parte proponemos ampliar aún más el campo de mira para sostener que desde el fin de la Segunda Guerra Mundial y el inicio de la Guerra Fría, se avizoró en Chile una escalada en el proceso represivo dirigido a neutralizar al movimiento obrero. Tal como ha demostrado para el caso de la minería del carbón la historiadora Jody Pavilack ${ }^{5}$, hacia el fin del período de Juan Antonio Ríos y la administración interina de Alfredo Duhalde la represión sistemática y ofensiva anti sindical fue realizada a través de diversos dispositivos que dan cuenta de una tendencia que ya se manifestaba dentro del radicalismo y los sectores conservadores. Podemos referir, por ejemplo, la recurrente apelación a los estados de excepción o los recursos de la Ley de Seguridad Interior del Estado; la activa participación de uniformados en política asumiendo cargos ministeriales, como fue la llegada del Vicealmirante Vicente Merino Bielich como Ministro del Interior y del general Manuel Tovarías Arroyo en Obras Públicas en enero de 1946.

También la designación de Jefaturas de Zona en Estado de Emergencia que daba amplias atribuciones a los autoridades militares y sus delegados para intervenir en la vida cotidiana, política y sindical a través del control absoluto en territorios considerados como conflictivos. A lo que habría que añadir la participación directa del personal uniformado en represiones de importante calibre como la matanza de la Plaza Bulnes ejecutada por un nutrido cuerpo policial. Aún más, el radical Alfredo Dhualde cumplió una amenaza que poco antes se había instalado durante la administración de Ríos con el fin de disciplinar el conflicto: suprimir la personalidad jurídica a sindicatos implicados en una huelga ilegal.

Por tanto, nos parece que es fundamental reconstruir y explicar la matanza de la Plaza Bulnes dentro de un encadenamiento de luchas desarrolladas en diversos puntos del país en que la clase obrera sindicalizada fue la fuerza motriz. La manifestación solidaria en protesta por los sucesos en la pampa salitrera que convocó a miles en Santiago tuvo un carácter nacional y se emparenta con la huelga del carbón desarrollada entre el 27 de diciembre de 1945 y el 15 de enero de 1946; con la huelga del salitre que se extendió desde el 17 hasta la primera quincena de febrero; con el paro nacional del 30 de enero, y del 4 al 8 de febrero del mismo año. Muchas de éstas apoyadas e impulsadas por el Partido

\footnotetext{
${ }^{4}$ Carlos Huneuus, La Guerra Fría Chilena. Gabriel González Videla y La Ley Maldita. Debate, Santiago, 2009. Brian Loveman y Elizabeth Lira, Las ardientes cenizas del olvido. Santiago, LOM-DIBAM, 2000, p.27-28.

5 Jody Pavilack, Mining for the Nation. The Politics of Chile's Coal Communities from the Popular front to the Cold War. University Park: The Pennsylvania State University Press, 2011. Sobre el anticomunismo y sus incidencias prácticas y discursivas dentro del proceso político chileno ver: Marcelo Casals Araya, La creación de la amenaza roja. Del surgimiento del anticomunismo en Chile a la "campaña del terror" de 1964. Santiago, LOM, 2016
} 
Comunista de Chile (PCCH) que a partir de la postguerra ampliaba sus bases de apoyo y su influencia en el movimiento sindical.

Si bien en este movimiento la huelga fue una herramienta poderosa de presión y confrontación que logró detener exitosamente la producción de sectores claves de la economía chilena, los trabajadores echaron mano de diversas formas de lucha con las que intervinieron y se empoderaron en el espacio público y colectivo para transmitir y socializar el descontento. Marchas, mítines o comicios, asambleas, impresión y distribución de panfletos, rayados, pancartas, publicaciones, junto a otras formas de acción directa provenientes de tradiciones de lucha de más larga data, como apedreamiento de vehículos, rompimiento de vitrinas, actos de sabotaje como corte de cables de tranvías y colocación de piedras en líneas férreas; repudio e incluso golpes a los rompehuelgas, juicios populares teatralizados en las quemas del mono, cierre violento de negocios e imponente presencia en los velorios, fueron formas de lucha que conformaron la densa textura de la protesta obrera y que permitieron desarrollar cuestiones simbólicas fundamentales como la afirmación, la cohesión y la ruptura de un orden considerado normal.

Lo fundamental en estas estrategias de confrontación y afirmación fue su carácter colectivo, campo de conformación de identidades. En este sentido, tal como subrayan diversos pensadores entre los que destaca el francés Pierre Bourdieu, cobran especial relevancia las organizaciones y los espacios de socialización en que se desenvuelve el conflicto, como el local sindical, las asambleas y la ocupación de las plazas, muy presentes en nuestro campo de mira: "La movilización de la clase obrera está ligada a la existencia de un aparato simbólico de producción de instrumentos de percepción y expresión del mundo social y de las luchas laborales, sobre todo porque la clase dominante tiende sin cesar a producir e imponer modelos de percepción y expresión que son desmovilizadores". 6 En efecto, los mecanismos represivos físicos y simbólicos con que respondió el sistema de dominación estuvieron dirigidos a neutralizar la potencialidad de ese "nosotros". Asesinatos, golpes, detenciones, hostigamiento, militarización de territorios, junto a otros tipos de violencia como despidos, cooptación y desafuero de dirigentes; allanamiento y cierre de locales sindicales; censura, y criminalización a través de los medios de comunicación.

\footnotetext{
${ }^{6}$ Pierre Bourdieu, "La Huelga y la acción política", En: Sociología y Cultura. Grijalbo, México, 1990. P.199. La importancia de la experiencia colectiva en la conformación identitaria recorre el grueso de la obra de E.P. Thompson, por ej: Costumbres en común. Barcelona, Crítica, 1995, orientación muy presente en esta investigación. Ver además: Agulhon, Maurice. El círculo burgués. Siglo XXI, 2009 y los trabajos de Mirta Zaida Lobato, en especial, La vida en las Fábricas: trabajo, protesta y política en una comunidad obrera, Berisso (1904-1970). Buenos Aires, Entrepasados/Prometeo Libros, 2001.
} 
A raíz de estas reflexiones, la hipótesis de este artículo postula que desde el fin del conflicto internacional se van moldeando las características de un nuevo ciclo represivo en Chile, categoría que transparenta los mecanismos coercitivos utilizados por el Estado para neutralizar la disidencia, disciplinar al movimiento obrero e imponer la paz social en la relación capital-trabajo. Pero que también nos da indicios sobre su contracara, la complejidad de la lucha de clases que permite visibilizar a través de la organización, afirmación e iniciativa colectiva de las minas, fábricas y calles.

Ambas dimensiones -represión y lucha- fundamentales para comprender la evolución del sistema político chileno durante la época de estudio, son los ejes que orientarán los objetivos de este artículo, dirigidos a reconstruir y analizar el intenso proceso de protesta obrera acaecido entre enero y febrero de 1946. Para este fin, además de recurrir a referencias hemerográficas, nos apoyaremos en fuentes primarias escasamente trabajadas por los historiadores, como los informes de la Sección Sindical y Confidencial de la Policía de Investigaciones de Chile y del sumario por los hechos ocurridos en la Plaza Bulnes.

\section{Huelgas obreras: de Sur a Norte}

Después de 1941 y la incorporación de Estados Unidos y la Unión Soviética a la Segunda Guerra Mundial, la línea estratégica del PCCH defendió con fuerza la tesis de la Unidad Nacional Contra el Fascismo. En este sentido, apelando al nacionalismo defensivo, se trataba de evitar los conflictos internos y propiciar alianzas que permitiesen mantener altos niveles de producción y asegurar el abastecimiento de materias primas estratégicas para las tropas aliadas. ${ }^{7}$

No obstante, si los comunistas moderaron sus presiones sindicales durante aquellos años- idea apuntalada con el fin de la III Internacional- finalizado el conflicto bélico, y con evidentes repercusiones de las críticas que levantaron sus compañeros franceses al Browderismo, se desarrolló una fuerte autocrítica que modificó su política estratégica. En efecto, en diciembre de 1945, en su XIII Congreso, el PCCH adoptó de manera formal la línea conocida como lucha de masas, elaboró un programa para acelerar la revolución democrática burguesa, presionar por la sindicalización campesina y una línea más dura en disputas laborales. A raíz de esta tendencia el hasta entonces Secretario General del PCCH Carlos Contreras Labarca fue fuertemente criticado por sus tendencias conciliadoras. Una señal en este sentido, fue su alejamiento del cargo casi un año más tarde, y la llegada de Ricardo Fonseca reconocido como "hombre más combativo" proclive a las luchas sociales.

Corrían promisorios tiempos para un PCCH que desde 1945 engrosaba sus filas con la incorporación de trabajadores, profesionales y destacados intelectuales motivados en parte por la exitosa actuación de los soviéticos en la definición del conflicto y la mística

\footnotetext{
${ }^{7}$ Andrew Barnard, The Chilean Communist Party: 1922-1947. Ph.D thesis, University of London, 1977
} 
emanada por entonces ${ }^{8}$. Los comunistas aumentaban su influencia dentro de los sindicatos con el control de las directivas del cobre, salitre y carbón, cuestión que le permitía no sólo dirigir una masa trabajadora de unos 50 mil hombres sino que eventualmente podía paralizar las fuentes productoras del $70 \%$ o más de las divisas que Chile necesitaba, y de un elemento fundamental para la industria y el transporte como el carbón ${ }^{9}$. Es decir, la influencia potencial era superior a su peso electoral que desde las elecciones parlamentarias de marzo de 1945 le permitió tener una representación parlamentaria de 15 diputados y 5 senadores ${ }^{10}$.

Con esto no queremos señalar que las movilizaciones que pronto presenciaríamos dependiesen simplemente de tal énfasis en la línea comunista, sino que las críticas, autocríticas e iniciativas dentro del PCCH eran acompañadas por una disposición ampliamente socializada entre las bases. Era un hecho concreto que el malestar de los trabajadores iba en aumento y que terminada la guerra no estaban dispuestos a seguir postergando sus demandas mientras las condiciones de vida se seguían deteriorando con la constante presión de la espiral inflacionaria por sobre los salarios.

Pero no sólo en los centros productivos fundamentales del país como la minería del carbón, cobre y salitre se desarrolló un potente movimiento huelguístico, también los años que siguieron al fin de la guerra son décadas en que poco a poco se multiplicaron los llamados hechos de masas en las ciudades, especialmente en la capital que crecía vertiginosamente en sus fronteras y habitantes. ${ }^{11}$ Se trata de años en que los sectores populares se desplazaron masivamente por el territorio nacional en búsqueda de mejores condiciones laborales prometidas por las políticas de modernización desarrollistas. Sólo entre 1940 y 1952 Santiago creció en un 38\%, llegando a concentrar un tercio de la población total del país en los años $\operatorname{sesenta~}^{12}$; con un mercado interno que lejos de expandirse al mismo pulso que el comercio y la industria manufacturera, acentuaba los niveles de desigualdad, inseguridad y exclusión de las mayorías. Junto a las frustraciones de un proceso de desarrollo y modernización truncado, se resintió el déficit de viviendas agravadas por las continuas alzas a los servicios y productos de consumo básico, como el pan, el azúcar y la harina.

Los sectores populares debieron saber organizarse para sobrevivir, así por ejemplo las Sociedades de Arrendatarios contras las alzas y desalojos, impulsaron tomas de terreno

\footnotetext{
${ }^{8}$ En un masivo acto realizado en el Teatro Caupolicán se incorporan al PCCH Pablo Neruda, Alejandro Lipschutz, Ángel Cruchaga Santa María, Juvencio Valle, María Marchant, entre otras personalidades del mundo del arte y la cultura. Ver: Jorge Arrate; Eduardo Rojas, Memoria de la izquierda chilena, Tomo I. Santiago, Javier Vergara Editor, 200, p.233

${ }^{9}$ Huneeus, op cit, p 77

${ }^{10}$ En las parlamentarias de marzo de 1945 fueron electos en la cámara alta: Elías Lafertte, Pablo Neruda y Salvador Ocampo que se sumaban a Carlos Contreras Labarca y Guillermo Guevara en mitad de sus períodos.

${ }^{11}$ Armando De Ramón, Santiago de Chile. Historia de una sociedad urbana. Santiago, Catalonia, 2007

${ }^{12}$ Sofía Correa Et, Historia del Siglo XX chileno, Santiago, Sudamericana, 2001, p 186
} 
como la ocurrida en General Velásquez el 28 de enero de 1946. La Federación Industrial Ferroviaria de Chile (FIFCH) por su parte, constituía una seria amenaza en un país movilizado en gran parte gracias a sus rieles y ya el 27 de diciembre de 1945 demostraba su fuerza y cohesión con una hora de detención de labores en protesta por el aumento de tarifas que provocaría el alza de los fletes y por lo tanto de las mercaderías. Por aquellos días también los panaderos de Santiago y Valparaíso anunciaban un paro contra la intensificación de la jornada sin el correspondiente aumento de salario.

Desde el mes de diciembre el conflicto en la minería del carbón se venía agravando, por lo que no fue una sorpresa que el año 1946 despuntase con una importante huelga en la zona, cuyo proceso ha reconstruido brillantemente Pavilack ${ }^{13}$. Las represalias a lo que comenzó con una disputa laboral en una mina relativamente poco importante (Colico Sur en Curanilahue) -como el despido de todos los trabajadores- motivaron el cierre solidario de toda la actividad en la región. A ellos se sumaron los mineros de Lota, Swager, portuarios, obreros de la fábrica de cerámicas, empleados ferroviarios ferrocarriles, etc. El presidente Juan Antonio Ríos amenazó por cadena radial que cualquier sindicato comprometido con una huelga ilegal perdería su personalidad jurídica. Las provincias de Concepción y Arauco fueron militarizadas bajo el decreto de Zona de Emergencia, al mando del Contraalmirante Holger Torres, que dio el ultimátum para volver a las faenas. ${ }^{14}$ Un ferrocarril con un destacamento de 150 fusileros, un carro con ametralladoras y municiones llegaron a Lota. El personal fue distribuido en diversos sectores de la industria. En tanto el crucero Chacabuco con infantería de marina desembarcó en Coronel para efectuar trabajos de vigilancia. Informaba El Siglo: "Los locales de los sindicatos se encuentran custodiados por fuerzas de carabineros, los dirigentes sindicales bajo estricta vigilancia policial y una estrecha censura se ha establecido sobre las comunicaciones entre los diferentes centros obreros."15

La huelga del carbón finalizaba entre el 11 y 15 de enero, con un proceso de negociación que ratificó la contratación de todos los mineros despedidos. La atención se concentró casi inmediatamente en las minas de nitrato de Mapocho en la provincia de Tarapacá y Humberstone, donde el 17 de enero comenzaba una huelga, debido según se ha sostenido, al drástico aumento de precios de los bienes de consumo básico en la pulpería ${ }^{16}$. Pero las razones del norte eran más bastas y estaban lejos de ser un tema secundario. En el mes de octubre de 1945 intempestivamente la Compañía Salitrera de Tarapacá y Antofagasta (COSATAN) modificó unilateralmente las condiciones de trabajo de sus obreros que habían sido acordadas con antelación en sus contratos. La capacidad de las bateas de 75 toneladas fueron aumentadas a 105 toneladas, sin que aumentara el salario. En

\footnotetext{
${ }^{13}$ Para la reconstrucción de esta huelga en detalle ver Pavilack, op cit.

${ }^{14}$ Ibid pp 136-141

${ }^{15}$ El Siglo 10 de enero, portada

${ }^{16}$ Véase Crisóstomo Pizarro, La huelga obrera en Chile, SUR, Santiago, 1986 p. y la prensa de la época.
} 
la sección máquinas sucedió algo parecido: de 8 toneladas por cada turno de 8 horas de trabajo fue aumentada en una tonelada más, sin que tampoco hubiese más remuneración". Igual cosa sucedió en el proceso de extracción de la pampa. ${ }^{17}$

Por aquellos días, debido al deteriorado estado de salud de Juan Antonio Ríos asumió como jefe de estado interino el senador Alfredo Duhalde, rico terrateniente del sur de Chile, perteneciente al ala derechista del Partido Radical. Entre sus primeras medidas emitió un Decreto de Zona de Emergencia en la región, envió fuerzas armadas y destructores de la marina al puerto de Iquique. El Jefe de Zona y Comandante en Jefe del cuerpo de Ejército del Norte, General Froilán Arriagada, nombró delegados a diferentes jefes militares para monitorear la pampa salitrera, designó al Jefe de la censura de la prensa, telegráfica y radiotelegráfica. Al día siguiente se les canceló la personalidad jurídica (amenaza que esta vez se cumplía) a los sindicatos implicados, comenzando por la clausura de sus sedes y desafuero de dirigentes.

No obstante, no tardaron en manifestarse las expresiones de solidaridad. El 24 de enero, 1.130 obreros del gremio salitrero de la Oficina Victoria de Iquique se declararon en huelga, uniéndose a un movimiento que para entonces comprendía a las oficinas Mapocho, Humberstone, Santa Lucía, Santa Laura, Kerima, Santa Rosa de Huara. ${ }^{18}$ El diputado comunista Cesar Godoy Urrutia, aprovechó el acto público organizado por los obreros de la Fábrica de Baldosas, realizado en la esquina de calle Lira con 10 de Julio para manifestar su indignación, dando cuenta de los ánimos confrontacionales que imperaban en el PCCH:

Este es un verdadero atropello que no se había visto ni aún durante los gobiernos más reaccionarios que ha tenido la nación. El gobierno debe reconsiderar su medida, porque de lo contrario la clase obrera hará caso omiso del "papelucho" que significa la personería jurídica, y en completa libertad, con ley o sin ella. Hará lo que más le convenga a sus intereses. ${ }^{19}$

Mientras más de una decena de barcos norteamericanos y británicos seguían varados en el puerto de Tocopilla esperando la carga de nitrato y muchos de ellos debieron zarpar sin las toneladas esperadas, la Confederación de Trabajadores de Chile (CTCH) convocó a una reunión urgente para protestar ante el gobierno y con votación unánime acordó convocar a un Paro Nacional de 24 horas que debería desarrollarse el 30 de enero. El conflicto ya era

\footnotetext{
${ }^{17}$ Sobre los cambios en la modalidad de trabajo en la oficina Mapocho véase Memorándum N50, 21 de enero de 1946. Sección Sindical, Dirección General de Investigaciones, Archivo Nacional de la Administración (ARNAD), Ministerio del Interior, volumen vol 12004. También El Siglo, 31 enero de 1946, p2 y Bernardo Araya, "Una CTCH Unida. Combatiendo en defensa de la clase obrera y el pueblo", II Conferencia Nacional de la Confederación de Trabajadores de Chile. Santiago, 1946, p.10

${ }^{18}$ Memorándum N59, 24 de enero de 1946, Sec. Sindical, Dirección General de Investigaciones, ARNAD, Min Int, vol 12004

${ }^{19}$ Memorandum N63. 25 de enero 1946, Sec. Sindical, Dirección General de Investigaciones, ARNAD, Min Int, vol 12004
} 
nacional y la contraparte no era simplemente las empresas patronales sino que los trabajadores apuntaban hacia el gobierno. Fue el primer paro nacional (y el último) convocado por la CTCH. Para promoverlo se harían manifestaciones solidarias a lo largo de Chile. Así el 28 de enero se realizó una concentración en la Plaza Bulnes de Santiago. Las cifras de asistentes emitidas por carabineros hablan de 2 mil personas, en tanto los organizadores de cinco mil.

\section{"Del trabajo a la Plaza Bulnes"}

La convocatoria de la CTCH llamaba a reunirse en horas de la tarde, después del trabajo, tal como acostumbraban realizarse las manifestaciones en el espacio público donde concurrían trabajadores $^{20}$. La plaza por lo demás era un lugar frecuente de encuentro, ubicada en pleno Barrio Cívico cerca de sedes sindicales y fuentes laborales. Pero ese lunes 28 de enero era distinto. Los testimonios coinciden en el asombro que provocó en los asistentes un despliegue policial de 250 carabineros, entre ellos 100 montados. Además de lo amenazante que podía ser la caballería y el uso de sables que acostumbraban portar como arma de servicio, se trataba de una cifra completamente desproporcionada para este tipo de eventos. Consideremos que la dotación de tropa para resguardar el orden público en manifestaciones del mismo tenor acostumbraba rondar entre los 70 a 90 hombres como máximo. Así, por ejemplo, en la conmemoración del $1^{\circ}$ de Mayo de 1945 realizada en la Plaza Constitución, la Prefectura Central de Santiago dispuso una fuerza compuesta de un mayor, un capitán, tres oficiales y 70 Carabineros; y en la concentración de la Federación Industrial y Ferroviaria de Chile, realizada en la misma Plaza Bulnes el 26 diciembre 1945, se dispuso una fuerza de cuatro oficiales y 80 carabineros. ${ }^{21}$

Por lo que aquí encontramos un primer elemento que debe considerarse en el desarrollo posterior de la Jornada. Del asombro, los manifestantes pasaron al estado de alerta cuando un grupo de carabineros rodeó el escenario ubicado frente a la estatua del General Bulnes. No era lo común que los uniformados se ubicaran entre medio de la gente. Aún más extraña resultó la orden dada por el Teniente Coronel Jorge Contreras Angulo para que en el costado norte del lugar, la tropa abriese un gran espacio, tipo elipse, entre el escenario y la Alameda. Nadie puedo explicar el sentido de dicha formación que dividió al público en dos, aunque se sostuvo más tarde a través de los medios de comunicación que fue dispuesto para facilitar el paso de las delegaciones de sindicatos.

Así lo recalcó en el transcurso de la investigación el tercer jefe presente en los hechos, Comandante Abraham Sánchez: "El Comandante Contreras ordenó la abertura de

\footnotetext{
${ }^{20}$ La reconstrucción de este apartado se basa en el Sumario por sucesos ocurridos en la Plaza Bulnes, Causa rol No 80-1946, Segundo Juzgado Militar de Santiago

${ }^{21}$ Sumario por sucesos ocurridos en la Plaza Bulnes, foja 306
} 
esa calle como de costumbre, para facilitar el acceso a la tribuna. El público que venía del lado Sur de la plaza entraba por los costados pero los dirigentes lo hacían por la calle misma" ${ }^{22}$ Pero la abertura de un espacio semejante no era una costumbre como coincidió la mayor parte de la tropa e incluso un oficial que se preocupó de dejar constancia de ello. Así lo estampó el Mayor Davis Valenzuela Valdivia: "yo no lo había visto con anterioridad; ni se había puesto en práctica nunca. Pues lo que se acostumbra es dejar un mínimum de tropa en el sitio de la manifestación y el grueso dejarlo aparte, de reserva en un lugar que se pueda llamar con facilidad." 23

Por su parte las delegaciones se quejaron que para ingresar a la plaza tenían que abrirse paso por el estrecho lugar que iba quedando libre entre carabineros y un apretado público apiñado en los costados. Entre ellos estaba el obrero de 23 años Carlos Salas Correa, del sindicato de la Compañía Chilena de Electricidad: "Yo presencié todo el desarrollo de los hechos y no ví a una sola delegación penetrar por el pasillo. Todas lo hacían por la calle Nataniel, cuando procedían del norte de la Plaza" ${ }^{24}$ También Moisés Valenzuela Zamorano Regidor, de 42 años, subsecretario de la Federación Nacional de Panificadores, coincide con esta apreciación ya que a pesar de formar parte de una nutrida delegación "compuesta de unas mil personas (...) no nos fue permitido entrar por el pasillo en forma de V que los Carabineros habían establecido, sino que tuvimos que hacerlo por sobre los prados" 25

Primero fueron los chiflidos contra carabineros e incluso las burlas como declararon diversos testigos entre ellos el diputado César Godoy Urrutia: “Alguien, a mi lado, hizo una observación jocosa: -¿Qué irá a bailar el general Maldonado?”. ${ }^{26}$ Pero en la medida que aumentaba la asistencia empezaron a generalizarse las fricciones y pifias de un público que se sentía cada vez más aprisionado en los costados de la plaza. Los gritos de ¡libertad! ¡que se vayan! y la entonación de la Canción Nacional se escuchaban con fuerza. Una orden y contraorden terminaría por caldear aún más los ánimos. Continúa el Mayor Valenzuela:

Volvió después mi Comandante Conteras y ordenó ensanchar más este espacio libre o pasillo. Yo ordené retroceder por mi lado como dos o tres metros a la gente, que obedeció, pero ya más molesta. Igual cosa hizo Guevara por su lado. Acto seguido, el Comandante Contreras encontró que el espacio era muy ancho y ordenó angostarlo, el público esta vez gustoso se adelantó, pero se adelantó demasiado, pues el Comandante Contreras estimó que se había angostado más de lo previsto por él, entonces volvió a ordenar que se ensanchara. Al cumplirse esta nueva

\footnotetext{
${ }^{22}$ Ibid f 764

${ }^{23}$ Ibid f 220

${ }^{24}$ Ibid f 635

${ }^{25}$ Ibid f 642

${ }^{26}$ Ibid f 103
} 
orden fue recibida por generales protestas y la gente ya no obedeció y se invadió todo el espacio libre. ${ }^{27}$

Para recuperar la posición original el Comandante Contreras hizo avanzar la caballería en fila india desde la Alameda por el Costado del Ministerio de Defensa. Seguramente los movimientos de ésta no fueron precisamente suaves, y un jinete cayó de su montura. A esa altura el público estaba furioso, al fragor del lanzamiento de pasto, palos y hasta maceteros, por un lado, y bastonazos de carabineros por otra parte, hubo varios contusos, principalmente civiles que cayeron al suelo. Mientras el roce se producía con mayor rigor en el nororiente de la plaza, alguien realizó un disparo y a continuación resonó por aproximadamente cinco minutos una descarga que muchos de los testigos asociaron posteriormente con ametralladoras y armas automáticas.

El público se replegó hacia el monumento, unos corrieron buscando refugio en calles y edificios cercanos, otros se tiraron al suelo, en tanto los carabineros retrocedían disparando hacia la Alameda. Así quedó en la memoria del subteniente Alfredo Cañas Gutiérrez de 23 años: "El tiroteo se hizo general, y vi claramente que algunos carabineros disparaban de pie y otros tendidos, de los que yo vi disparar, pude apreciar que lo hacían al aire, hacia arriba. A mí me dio la impresión de que toda la infantería estaba disparando"28.

Además de Ramona Parra fueron asesinados los obreros Filomeno Chávez, César René Tapia, Manuel López, Adolfo Lisboa y Alejandro Gutiérrez. Algunos manifestantes recibieron entre dos a cuatro balas en el cuerpo, como fue el caso del panificador José Painecura de 23 años $^{29}$. Otros no se explican cómo pudieron salvarse. Así testificó Pedro Guzmán Fierro, albañil del Sindicato de la Compañía de Electricidad: "Delante de mí a poca distancia vi caer a cuatro compañeros y en mis pies rebotó una bala también felizmente sin lesionarme. Mis compañeros cayeron heridos y en seguida ayudé a colocarlos en ambulancias y esto hice con varios más."

Esa tarde se dispararon 256 balas, según el informe del fiscal militar Enrique Leyton Garavagno, que entre las primeras medidas solicitó el recuento de municiones gastadas. Como era previsible, en el proceso de interrogatorio los carabineros que dispararon aseguraron haberlo hecho al aire o al suelo sin mediar una orden previa -cuestión fundamental en la que indagaba el proceso- sino que al sentirse intimidados y agredidos por civiles, a quienes además culparon de haber disparado primero. Ejemplo de ello fueron las declaraciones del Almirante Merino Bielich, recién nombrado Ministro del Interior que aunque no estuvo presente en los sucesos se encargó de difundir su versión ante la prensa: "Retirándose los carabinaros de a pie, recibió uno de ellos una pedrada en la cabeza y

\footnotetext{
${ }^{27}$ Ibid fojas 219-220

${ }^{28}$ Ibid fojas 471-472

${ }^{29}$ Ibid f 613

${ }^{30}$ Ibid fojas $630-31$
} 
numerosos palos fueron lanzados, sonando, además, unos tiros que provenían del populacho, cayendo dos carabineros. En este momento los carabineros sacaron sus pistolas y dispararon." 31

Algunos uniformados acusaron a los manifestantes de estar en estado de ebriedad, aunque ni la autopsia ni los partes de los heridos respaldaron esa impresión. Coinciden además en que no se utilizaron ametralladoras, solo sus armas de servicio. De los 190 interrogados sólo tres repararon en los civiles derribados, en cambio la gran mayoría refiere a sus compañeros golpeados o heridos que fueron contabilizados en seis.

Por otra parte, el voluminoso expediente contiene varias líneas de indagación posibles que no fueron agotadas. Por ejemplo, la fiscalía no solicitó desde un comienzo la relación de armas y municiones de los Jefes y Oficiales. Se conformó con la de la tropa y dio por hecho que ellos no habían disparado porque así lo aseguró la jefatura. La investigación tampoco pudo explicar por qué ese día, varias horas antes de los incidentes, se había ordenado por telefonema a todas las comisarías el reclutamiento de tropas, que posteriormente el Jefe de la II zona que comandó la orden justificó "por haberse observado que numeroso público que desde las 16 horas se encontraba reunido", a la que agrega su manifiesta "hostilidad". ${ }^{32}$ No obstante saber -porque así lo constatan la gran mayoría de testigos y periodistas presentes- que a esa hora era muy poco el público reunido. Tampoco pudo explicar por qué entre seis y siete de la tarde la Prefectura General solicitó a las Comisarías de la guarnición que enviaran a la plaza todo el personal disponible. ${ }^{33}$

Lo que quedó claro es que en cuanto terminó el fuego la gente enfureció: "el público se abalanzó en contra nuestra con piedras, palos e insultos". ${ }^{34}$ Así lo ratificaba el cabo Víctor Hernández Parra, de 32 años: "Una vez terminados los incidentes y cuando estábamos formados para retirarnos, se acercaron varias personas y nos empezaron a insultar tratándonos de asesinos y masacradores". 35 Los implicados no lo niegan. El tornero mecánico Daniel Cepeda Tapia reconoció que: “al ver a los caídos nos indignamos y todo el público comenzó a lanzar palos sacados de los marcos de los motes, los cuales eran lanzados al grupo de carabineros que acababa de disparar ${ }^{36}$

Posteriormente cubrieron con la sangre regada en la plaza sus estandartes y salieron en desfile hacia la Alameda. Los testimonios y las crónicas informaron sobre diversos desórdenes en las calles céntricas, en que grupos de manifestantes apedrearon automóviles, dieron vuelta una caseta de carabineros y otros trataron de cortar los cables de los tranvías. El Mayor Rómulo Guevara dejó constancia de ello: "Una vez en el cuartel, el oficial de

\footnotetext{
${ }^{31}$ Ibid f 323

${ }^{32}$ Documento Confidencial N ${ }^{\circ} 248$ A la Primera Fiscalía Militar de Santiago firmado por Domingo Pizarro Vargas, General de Carabineros y Jefe de la III Zona, Santiago, Ibid f 908

${ }^{33}$ Ibid f 765

${ }^{34}$ Ibid $\mathrm{f} 714$

${ }^{35}$ Ibid f 344

${ }^{36}$ Ibid f 685
} 
servicio de Población, Subteniente Blanco, me dio cuenta que los manifestantes habían cometido numerosos desmanes, rompiendo las vitrinas de algunas tiendas"37

Al parecer no eran los únicos enardecidos. El Teniente Roberto Lizana Rodriguez, 26 años de Traiguén relata que a raíz de las heridas que sufrió al comienzo de los incidentes el capitán Oshilewsky, debió llevarlo a la posta central, pero una vez atendido tuvo que "sacarlo por la puerta falsa, pues según se me informó, en la calle un grupo numeroso nos esperaba con el evidente propósito de agredirnos. Personal de choferes y practicantes de la Posta que salían en ambulancias, nos hicieron objeto de toda clase de injurias." ${ }^{38}$ Esto coincide con los recuerdos de Orlando Millas, cuando señala que posteriormente a la matanza se encabezó un desfile de protesta hacia la Asistencia Pública ubicada a pocas cuadras de los hechos. Luego era importante dar a conocer lo sucedido, por eso no extraña que la marcha se dirigiese hacia diversos medios de comunicación. Señala Millas: "entramos por Mac Iver hasta el local de "El Siglo", seguimos para pasar y volver a pasar ante La Moneda, enfilamos frente al diario "La Nación", volvimos por Moneda ante "El Diario Ilustrado", continuamos por Morandé a "El Mercurio", desembocamos a la Plaza de Armas. $^{39}$

Entre las consecuencias por los sucesos de la Plaza Bulnes se desencadenó una crisis política que condujo a la renuncia del Ministro de Obras Públicas Eduardo Frei Montalva que fue reemplazado por el general Manuel Tovarías Arroyo. Por su parte, Duhalde nombró como Ministro del Interior al Jefe de escuadra, almirante Vicente Merino Bielich. Entre sus primeras medidas declaró Estado de Sitio en todo el país, que justificó:

Por el estado de ajitación extremista que reina en todo el territorio nacional. No ignoran nuestros conciudadanos la forma ilegal en que los obreros del norte del país han planteado sus peticiones; ni le son desconocidos el asalto a una población de la Caja de la Habitación ni la agresión armada que elementos exaltados han perpetrado en la persona de numerosos elementos del cuerpo de Carabineros que cumplían con su deber de resguardar el orden. ${ }^{40}$

Haciendo referencia al intento de toma de terrenos realizada el 28 de enero se culpaba a los movilizados de la matanza de la Plaza Bulnes y de los atropellos laborales que impulsaron las huelgas del norte. Con este decreto los barcos de la armada se pusieran en alerta e incluso la Municipalidad de Santiago cayó bajo la jurisdicción del comandante. Se dio orden de impedir la difusión de los sucesos y se emitieron órdenes de allanamiento a sedes

\footnotetext{
${ }^{37}$ Ibid fojas 45-46y 309 ver: El Diario Ilustrado, 29 de enero de 1946, p 4

${ }^{38}$ Ibid f 309

${ }^{39}$ Orlando Millas, En tiempos del Frente Popular, I volumen, Santiago, Cesoc Ediciones, 1993, p. 462

${ }^{40}$ Declaración al país del Ministro del Interior Vicealmirante Vicente Merino Bielich. 28 enero 1946, ARNAD, Min Int, vol 12004
} 
sindicales y varios diarios, entre ellos El Siglo, acusado de "incitar a la revuelta". Su director fue detenido junto a otros dirigentes entre ellos los consejeros de la CTCH Roberto Pérez Nuñez, Ramón Ayala, Juan López, Nazario Salinas, Juan Briones, Evaristo Guzmán y Juan Valencia. ${ }^{41}$

Este tipo de agravios sólo intensificaron la crisis. El recelo y la indignación fueron socializados en las diversas asambleas que se desarrollaron desde esa misma noche y se plasmaron en el pliego levantado por la CTCH.

\section{El Paro Nacional del 30 de enero}

A pesar de los arrestos de algunos de los principales dirigentes de la CTCH y de otros dirigentes sindicales acusados de infringir la Ley de Seguridad del Estado las protestas obreras continuaron en las semanas siguientes. Como respuesta inmediata la CTCH reforzó la idea del paro por 24 horas y duelo nacional para el día 30 de enero. No obstante con anterioridad a la fecha fijada comenzaron a producirse paros parciales. En cuanto a la coordinación y paralización de centros productivos neurálgicos, del comercio, transporte y otros gremios, dirigidos y ejecutados por un movimiento sindical unido y empoderado, este fue uno de los paros nacionales más exitosos que registre la historia de Chile, pero curiosamente aún adolece de monografías que den cuenta de las dinámicas internas dentro del proceso de lucha de clases en que se sitúa. ${ }^{42}$ En el centro de la protesta estaban agravios recientes como la masacre de Santiago, la cancelación de la personalidad jurídica a los sindicatos del norte y -lo que escucharemos recurrentemente en asambleas y actos públicos- la indignación ante la presencia de militares tanto en el espacio local (militarización de territorios y lugares de trabajo) como en el nacional (gabinete).

Esa misma noche detuvieron sus labores 3.200 obreros mineros de Sewell ${ }^{43}$, al día siguiente se sumó el importante gremio de los ferroviarios de todo el país obligando a los inspectores y personal del Ejército a hacerse cargo; también se unieron 9.500 empleados y obreros de El Teniente en Rancagua, y poco después, aprovechando de pedir más seguridad para su trabajo, comenzó en la Mina Despreciada de Tocopilla con el primer turno de la tarde. ${ }^{44}$ Lo mismo hicieron los mineros de La Plegaria y Curanilahue; ${ }^{45} 29.262$ obreros del mineral El Navío al interior de Nogales ${ }^{46} ; 14$ mil en Lota y Schwager; 105 en Colico Sur en

\footnotetext{
${ }^{41}$ El Siglo, 30 de enero 1946, portada

${ }^{42}$ Una excepción es el aporte hecho por Crisóstomo Pizarro, op cit, a través de la prensa de la época.

${ }^{43}$ Santiago, 29 de Enero de 1946, Sec. Sindical, Dirección General de Investigaciones, ARNAD, Min Int, vol 12004

${ }^{44}$ Oficina de Partes, Carabineros de Chile, 29 de enero de 1946, ARNAD, Min Int, vol 12004

45 Memorandum No74. Santiago, 29 de Enero de 1946, Sec. Sindical, Dirección General de Investigaciones, ARNAD, Min Int, vol 12004

${ }^{46}$ Radiograma, Servicio de radiocomunicaciones de Carabineros de Chile, 29 enero de 1946, Sec. Sindical, Dirección General de Investigaciones, ARNAD, Min Int, vol 12004
} 
Arauco; 250 obreros de mina y superficie de la Compañía Carbonífera Victoria de Lebu; 1200 obreros de las oficinas Alianza, Pan de Azúcar y Diez de Septiembre.

Sobre esta escalada la Sección Sindical de la Dirección General de Investigaciones advertía en su informe: "Han continuado desarrollándose en el país diversos otros actos y comicios públicos." ${ }^{47}$ Se informaba que en Valparaíso los gremios marítimos (tanto estibadores como obreros del puerto y de distintas compañías de navegación) marcharon desde la aduana hasta la Plaza O’Higgins para realizar un comicio en el que ratificaron su adhesión al paro; en tanto en Viña del Mar se reunieron en la Plaza Vergara los sindicatos profesionales. Además del salitre dónde aún no habían regresado a sus trabajos, la prensa anunciaba la adhesión de los mineros del cobre y del carbón. La unión de profesores, los obreros de CHILECTRA, de agua potable y de gas, los molineros, choferes y cobradores de autobuses, del comercio detallista incluido el sindicato profesional de peluqueros, de empelados de organizaciones hotelera, de carnicería y beneficiencia. ${ }^{48}$

Conocemos otros detalles del paro gracias a las fluidas comunicaciones que mantuvieron intendentes y prefectos de carabineros con el Ministerio del Interior. Así por ejemplo, el Intendente de Valdivia, Víctor Soto Echeñique informaba: "Me permito poner en conocimiento de que hoy se han paralizado distintas actividades de la ciudad con ocasión paro general país sin que se produzcan incidencias alguna" 49 Lo propio hacía el Intendente de Tarapacá Enrique Brenner: “Además de los sectores en huelga adhieren al paro oficinas Camina Gloria, Aguada e Iris y demás gremios de movilización urbanos y rurales. Compañía alumbrado trabajando con personal reducido ${ }^{50}$.

El día 30 estaba involucrada la totalidad del gremio salitrero de la Provincia de Tarapacá (19.403 obreros) y Antofagasta (28.373). En el norte del país se notificaba la adhesión de todos los sindicatos de Iquique, La Serena, Coquimbo, Ovalle, Combarbalá e Illapel. Desde el sur se recibían noticias de Concepción incluyendo por supuesto la totalidad de la zona minera e industrias anexas, Arauco, Los Ángeles, Bío Bío. En la pequeña localidad de Licantén, tanto el maquinista como el fogonero se negaron a trabajar paralizando el recorrido y escandalizando a los latifundistas.

Algunos telegramas acusaban impuntualidad ya que a raíz del paro se registraron diversos problemas derivados de la falta de corriente. "No habrá luz hoy en San Antonio, Cartagena y Llo-Lleo" advertía el parte de carabineros. Lo mismo en Aconcagua y Valparaíso dónde el servicio estuvo interrumpido toda la mañana. El ruidoso puerto detuvo sus cargamentos, tranvías, micros y góndolas, fábricas e industrias. Por su parte, Luis Uribe

\footnotetext{
${ }^{47}$ Memorandum No72. Santiago, 29de Enero de 1946, Dirección General de Investigaciones Sección Sindical, ARNARD, min int, vol 12004

${ }^{48}$ El Diario Ilustrado, 30 de enero de 1946, p. 2

${ }^{49}$ Telegrama del Intendente de Valdivia dirigido al Ministerio del Interior, 30 enero de 1946, ARNAD, Min Int, vol 12004

50 Telegrama del Intendente de Tarapacá dirigido al Ministerio del Interior, 30 enero de 1946, ARNAD, Min Int, vol 12004
} 
Gobernador de San Antonio informaba: "Hoy se efectuó paro general en todas las actividades del puerto incluso alumbrado. Comercio funciona regularmente." "51 En definitiva, según las propias fuentes oficiales hubo muy pocas ciudades en que el paro fue solo parcial.

La zona interurbana de la capital también se unía. Renca, Puente Alto, Talagante, Peñaflor, Maipu, San Eugenio y San Bernardo se veían afectados por la paralización de maestranzas, fábricas, panaderías y comercio en general, y de las plantas eléctricas de La Carena, Queltehues, Maitenes y La Florida que intentaban funcionar con personal del Ejército y de la Marina, custodiados por Carabineros. Lo mismo en la planta eléctrica de Maipo (Buin): "Se deja constancia además, que el servicio de movilización colectiva de San Antonio a Melipilla y Santiago; de Buin, San Bernardo y La Cisterna a Santiago y de Talagante-Peñaflor y Maipú a Santiago se encuentra totalmente paralizada". 52

En Santiago, durante la madrugada del día 30, al paro de los obreros de la compañía de luz, se sumaba que "fueron cortados casi en su totalidad los cables de alta tensión de las torres de la Compañía de Electricidad en Peñalolén, motivo por el cual hay poca corriente eléctrica para la ciudad"53. La ciudad amanecía con la portada de El Siglo que titulaba "Chile no va hoy a la Fábrica", y en efecto, parecía vivir un día festivo por la escasez de locomoción colectiva en general, incluyendo tranvías, autobuses y microbuses, en todas sus líneas y la gran mayoría del comercio, como almacenes y panaderías. En tanto, en la zona sur se sumaba además el Matadero Municipal y la Central de Leche. En el sector norte las fábricas y construcciones, los establecimientos del Frigorífico San Cristóbal y de la Compañía de Cervecerías Unidas estaban detenidas. En tanto en Santiago centro, además no funcionaban teatros, cines ni el FFCC eléctrico a Puente Alto. En general los hospitales, postas, oficinas de correos y telégrafos funcionaron normalmente aunque afectados por falta de movilización. ${ }^{54}$

Quienes no paralizaron sus ruedas o faenas se expusieron a enfrentar el castigo popular. Un parte de carabineros acusaba que en horas de la mañana, un grupo de mil personas entre las que se encontraba el diputado comunista Humberto Abarca "y otro cuyo nombre se ignora", iban marchando por calle veintiuno de mayo, esquina Monjitas en dirección a Plaza de Armas cuando encontraron una fuente de soda abierta a cuyo dueño instaron a cerrar:

\footnotetext{
${ }^{51}$ Telegrama del Gobernador de San Antonio al Ministerio del interior, 30 de enero 1946, ARNAD, Min Int, vol 12004

${ }^{52}$ Comunicación $\mathrm{N}^{\circ} 246$, Prefectura rural Santiago dirigido a la Jefatura de la Tercera Zona de Carabineros, 30 de enero 1946, ARNAD, Min Int, vol 12004

${ }^{53}$ Comunicación N544, Prefectura General de Santiago, dirigido a la Dirección Nacional de Carabineros "Santiago", 30 enero 1946, ARNAD, Min Int, vol 12004

${ }^{54}$ Comunicación N ${ }^{\circ} 443$ Coronel Guillermo Galindo, Prefecto General de Santiago, dirigido a la IIIa Zona de Carabineros "Santiago", 30 enero 1946 ARNAD, Min Int, vol 12004
} 
En vista de que dicho señor no accediera a tales exigencias, el Diputado señor Abarca, al mando de la gente que lo seguía, procedió a apoderarse en forma violenta de la fuente de soda ya referida, tomando la cortina del citado local, la bajaron bruscamente, haciéndola salir de los rieles laterales y obligando al personal a retirarse del negocio. ${ }^{55}$

Por otra parte, señalaba El Diario Ilustrado que: "el camión repartidor de pan, patente YN1001, fue asaltado por un grupo de individuos que, luego de obligar a su conductor a abandonar el vehículo, se entregaron al saqueo de las mercaderías que llevaba".56 Además, la Prefectura del Tránsito notificaba que grupos de individuos apedrearon a los automóviles que no respetaron el paro en Franklin con San Diego; Estado esquina Agustinas y en diversas intersecciones de la Alameda como Estado, Serrano y San Diego. En tanto frente al diario El Imparcial, "grupos de individuos apedrean edificios y vehículos que pasan por dicha calle". ${ }^{57}$ Más de una decena de personas fueron detenidas en Mapocho con Matucana y puestas a disposición de los Tribunales, acusadas de arrojar piedras a micros y góndolas, obligando a los pasajeros a bajarse e incitar a la huelga a los trabajadores de la Barraca Iberia ubicada en Matucana $N^{\circ} 745$. En tanto en el mismo sector, el ciudadano Luis Ernesto San Martín fue sorprendido cuando -con el mismo propósito- pronunciaba un discurso a más de 200 obreros de la Fábrica de Escobillas y Jabones en calle Chañarcillo esquina Matucana: "siendo agredidos los Carabineros por la multitud allí instalada" al intentar retenerlo. 58

Pero hubo otro suceso que repercutió en la memoria popular movilizando las emociones. En la capital la interrupción de faenas, la subversión del tiempo del orden y la reproducción de la vida hizo aún más significativo el sepelio de las víctimas de la Plaza Bulnes. Incluso El Diario Ilustrado dedicó un importante espacio a los "imponentes funerales de las víctimas", encabezados por más de doscientas mil personas. ${ }^{59}$ En diversas fotografías que quedaron como testimonio se puede observar el cortejo que acompañó los féretros de las víctimas en una solemne marcha que partió desde el local de la CTCH ubicado en Santo Domingo N¹837, dónde eran velados, hasta el cementerio general.

A través de un corredor que demarcó una delegación de ciclistas, los carros fúnebres repletos de arreglos florales, avanzaron en medio de una nutrida columna que siguió su curso por calle Morandé, el barrio Mapocho en cuyos puentes de antaño se apiñaban los

\footnotetext{
${ }^{55}$ Comunicación N542 Coronel Guillermo Galindo, Prefecto General de Santiago, dirigido a la Dirección general de Carabineros, 30 enero 1946 ARNAD, Min Int, vol 12004

56 EL Diario Ilustrado, 31 de enero de 1946, portada

${ }^{57}$ Comunicación N`544 Coronel Guillermo Galindo, Prefecto General de Santiago, dirigido a la Dirección Nacional de Carabineros "Santiago", 30 enero 1946 ARNAD, Min Int, vol 12004

${ }^{58}$ Comunicación N76 Coronel Guillermo Galindo al Ministerio del Interior, 31 enero 1946, ARNAD, Min Int, vol 12004

59 El Diario Ilustrado, 31 enero 1946
} 
obreros para ver pasar el cortejo, hasta confluir en Avenida La Paz. El ardiente sol de fines de enero fue mitigado gracias a la intervención de voluntarios de la Defensa Civil que aportaron con baldes, botellas y tarros de agua para refrescar la marcha de decenas de delegaciones y familias que querían estar presentes esa mañana.

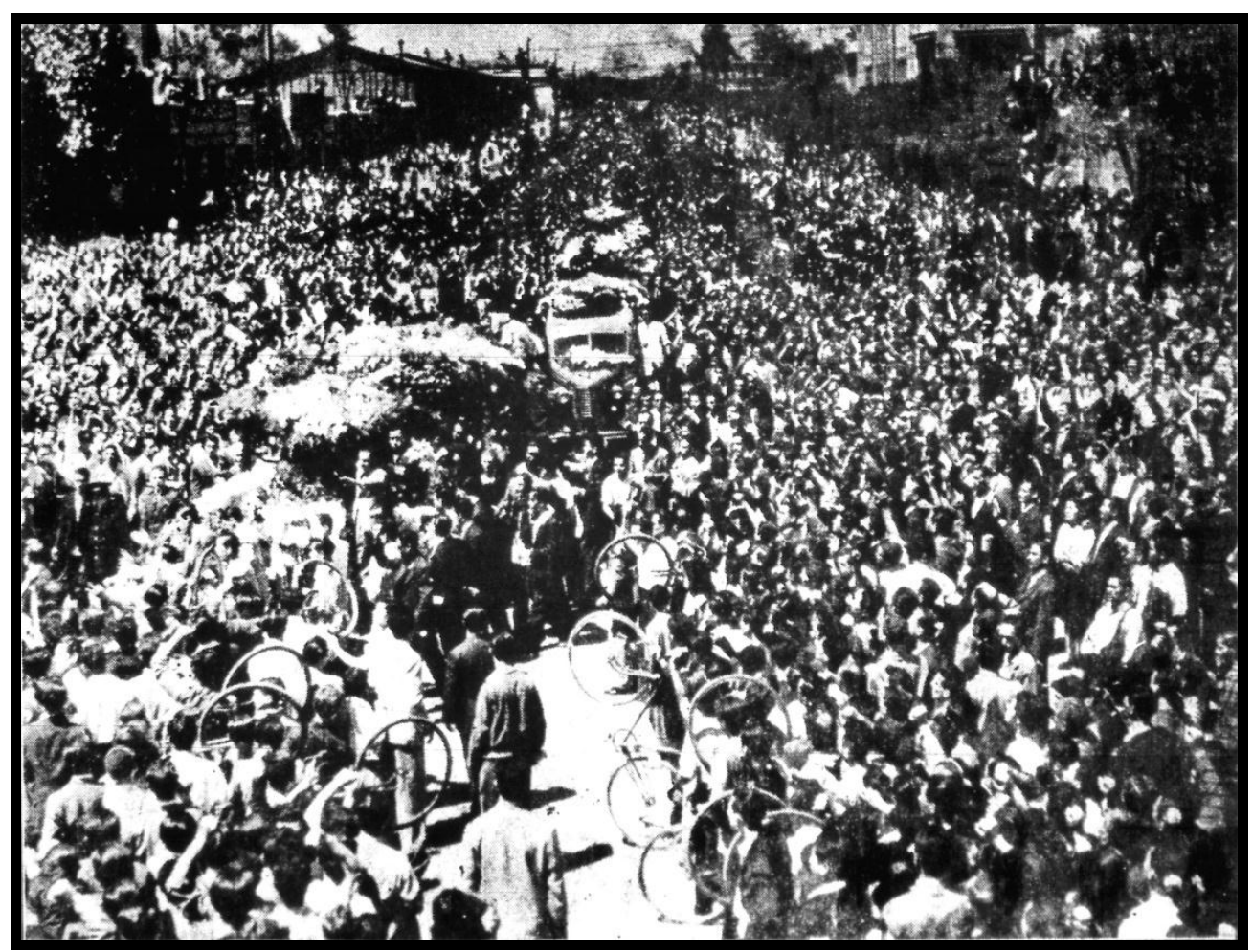

Foto $\mathrm{N}^{\circ} 1$. Por Avenida de La Paz, el cortejo fúnebre llega al Cementerio General. La Nación, 31 de febrero de 1946

Tal como solicitaron los organizadores, en el recorrido no hubo un solo policía, lo que permitió que se desarrollara en tranquilidad y sin provocaciones. Apuntaba emotivamente un reportero de El Siglo:

El silencio de la ciudad toda, con los negocios cerrados, sin el agrio bocinazo de los micros y autobuses, la limpidez del cielo sin el humo de las chimeneas, las máquinas en las fábricas respetando el silencio, inmóviles y grises las ventanas de las casas negreando en cabezas calladas. Las brillantes líneas de los tranvías, descansando sin carros. Todo se contristaba al paso de los seis muertos en la Plaza Roja. El silencio lleno de la indignación del pueblo vibraba en el aire. ${ }^{60}$

\footnotetext{
${ }^{60}$ EL Siglo 31 de enero de 1946, contraportada
} 
Frente al mausoleo del Sindicato de las Cristalerías de Chile donde serían enterrados las víctimas, representantes de fuerzas políticas, estudiantiles, sindicales dirigieron emotivas palabras. Entre ellos, el diputado comunista Bernardo Araya, Subsecretario General de la CTCH dio a conocer el pliego de peticiones y advirtió que si para las 18 horas la respuesta del gobierno no era favorable, el paro continuaría con carácter indefinido.

En horas de la tarde el pliego de 12 puntos fue entregado personalmente a Duhalde por el propio Araya, Arturo Velásquez, Esterfio Silva, Guillermo Sánchez y el diputado radical Raúl Juliet y daba cuenta de un abanico de problemas bastante amplio. Entre ellos se exigía cuestiones urgentes como la derogación del Estado de sitio, la indemnización a las familias de las víctimas, la rehabilitación inmediata de la personalidad jurídica de los sindicatos del salitre, la derogación de la Ley de Emergencia y retiro de las fuerzas armadas en la intervención de los conflictos del trabajo. Pero además incluía demandas democratizadoras más profundas como la constitución de un gobierno civil de izquierda, la aplicación de medidas drásticas contra las empresas patronales que no cumplen los convenios y disposiciones arbitrarias, impulsar la sindicalización campesina e interrumpir relaciones con la España de Franco y la dictadura militar de Farrell en Argentina.

Lejos de dar una respuesta directa, Duhalde salió del paso advirtiendo que los obreros primero debían volver al trabajo antes de derogar el estado de sitio, el resto no lo podía resolver de inmediato ya que se encontraba bajo un gabinete transitorio. Los dirigentes esperaban que después de la "imponente manifestación de sentimiento colectivo" y del éxito del paro nacional, las fuerzas políticas de izquierdas logarían presionar por la constitución de un gabinete civil y democrático que asegurase el cumplimiento de sus demandas. Si bien los obreros de Mapocho y Humberstone continuarían la huelga hasta que no se restableciera la personalidad jurídica de sus sindicatos y se escuchara sus demandas, al día siguiente los trabajadores se reintegraron a sus puestos.

Aunque la CTCH advertía que "Permanecerá vigilante frente al compromiso del gobierno en el cumplimiento de los puntos entregados por la $\mathrm{CTCH}^{\text {"61, }}$, retrospectivamente no faltaron las críticas sobre esta decisión y confiar en una respuesta positiva, en vez de aprovechar la correlación favorable de una clase obrera unida y movilizada en asambleas y en las calles. ${ }^{62}$

\section{El Paro de Febrero y la división de la CTCH}

Febrero no empezó bien. Las conversaciones entre el Partido Radical y el Partido Democrático con el gobierno no daban frutos y éstos decidían retirar a sus ministros. En lo que fue condenado como un acto de censura inaceptable fueron requisados el diario El

${ }_{62}^{61}$ El Diario Ilustrado, 31 de enero de 1946, portada

${ }^{62}$ Araya, op cit. p. 12 
Siglo, las revistas Topaze y Sensación. Tampoco había llegado la respuesta anhelada al resto de los 12 puntos. Después de arduas asambleas y reuniones el Consejo Directivo Nacional de la CTCH -entre ellos su Secretario General, el socialista Bernardo Ibáñez Secretario General - y los delegados de 22 federaciones, votaron por convocar a un nuevo paro general con carácter de indefinido que se iría concretando parcialmente desde el mismo día 2 hasta hacerlo general el lunes 4 de febrero.

Los presentes salieron decididos a transmitir la información a sus bases. Nadie de ellos dudó hasta entonces de la palabra del Bernardo Ibáñez. Pero paralelamente en La Moneda se realizaba otra reunión que se prolongaría hasta la madrugada, cuyas consecuencias repercutirían no sólo en la coyuntura política sino que se extendería como una sombra durante largos siete años hasta que el movimiento sindical logró sobreponerse en 1953 con la conformación de la Central Única de Trabajadores (CUT).

Se supo en la mañana: Los socialistas aceptaban el ofrecimiento de participar en el nuevo gabinete de Alfredo Duhalde con cuatro importantes cargos ministeriales (Economía, Agricultura, Trabajo y Salubridad). Compartirían carteras con tres militares (Interior, Defensa y Obras Públicas), tres radicales (sancionados por el partido), un democrático y un independiente. La elección de este gabinete profundizó la crisis dentro del sistema político chileno. Hasta entonces existían expectativas tanto dentro del PCCH, del Partido Radical y una fracción del socialismo de lograr consensuar un gobierno progresista de izquierda que excluyera definitivamente a los militares de sus carteras y que garantizase un proceso democrático para la resolución de los conflictos que consideraban más apremiantes.

No sabemos con certeza pero podemos presumir que la opción de Duhalde contempló solicitar al PS la finalización del paro, para ello contaban con una figura clave. Así la voz del Bernardo Ibáñez, Secretario General del PS y de la CTCH se dirigió al país en cadena radial nacional llamando a no participar de una movilización que acusó de ser orquestada por el Partido Comunista, por lo tanto se trataba de una "instrumentalización política", argumentando que ya se había conseguido los propósitos de los trabajadores ${ }^{63}$. Para respaldar el manifiesto, el gobierno se adelantó a restablecer la personalidad jurídica de los sindicatos. Por ello aclaró: “A petición de los señores Ministros socialistas (...) restablece el beneficio de la personalidad jurídica a los Sindicatos Mapocho y Humberstone en la provincia de Tarapacá."64

Acusando el golpe, Bernardo Araya aclaró que las demandas eran mucho más amplias:

El paro nacional no está resuelto con la devolución de la personalidad jurídica a los sindicatos, se precisa el retiro de la demanda por parte de la empresa contra estos organismos, la gente de las salitreras sigue

\footnotetext{
${ }^{63}$ El Diario Ilustrado, 6 de febrero de 1946, portada.

${ }^{64}$ Telegrama del Ministro del Interior al intendente de la provincia de Tarapacá, Santiago, 3 de febrero de 1946. ARNAD, Min Int, vol 12004
} 
desalojada de sus campamentos y durmiendo en la vía, mientras las tropas tienen ocupadas las faenas; los obreros exigen el pago de indemnización de los obreros caídos en la Plaza Bulnes ${ }^{65}$.

Si bien las hostilidades dentro de la $\mathrm{CTCH}$ eran frecuentes entre comunistas y socialistas, hasta entonces se anteponía la valoración de la mayoría con el fin de preservar la unidad sindical. ${ }^{66}$ No son pocas las evidencias de los acalorados debates y descalificaciones entre ambos partidos, como por ejemplo, los suscitados el 26 de enero a raíz de la supresión de la personalidad jurídica a los sindicatos del nitrato. Sobre aquella reunión informaba al Ministerio del Interior la policía de investigaciones:

Bernardo Ibáñez Águila hizo una extensa exposición sobre la situación del norte del país, criticando acerbamente el procedimiento del Partido Comunista, al que hizo responsable de lo ocurrido en los sindicatos obreros de Iquique. Por su parte, el grupo comunista, encabezado por el Senador Salvador Ocampo, interrumpió violentamente al Sr. Ibáñez, expresando ese senador que el Partido Comunista asumía toda la responsabilidad de los hechos acaecidos en el norte del país, agregando que los Cuadros del Partido estaban dispuestos hasta a salir a la calle, si así era preciso obrar con el objeto de defender las conquistas de los obreros chilenos. ${ }^{67}$

En esa como en otras oportunidades la reunión en que participaban la totalidad de Consejeros Nacionales y los principales dirigentes de los gremios ferroviarios, tranviarios, de la Cía de Electricidad, gas, teléfono, etc. se selló con un plan operativo en conjunto del que hemos dado cuenta. Hasta entonces esa era la tónica de las reuniones acaecidas en Santo Domingo $\mathrm{N}^{\circ} 1837$. Pero esta vez se trataba de una ruptura sindical irreconciliable ya que iba en contra de los acuerdos consensuados por el Consejo Directivo Nacional.

A partir de entonces las disputas entre la fracción socialista y comunista de la $\mathrm{CTCH}$ se intensificaron en asambleas, concentraciones y en la misma presencia (o ausencia) durante el paro. Por esta razón es aún más difícil dimensionar la actividad huelguística y protesta obrera durante el paro del 4 de febrero. Si intentamos rastrearlo por

\footnotetext{
${ }^{65}$ Las Noticias de Última Hora, 5 de febrero de 1946

${ }^{66}$ Sobre las tensas relaciones entre el PS y PCCH al interior de la CTCH, ver el estupendo aporte de Cristián Pozo "Ocaso de la unidad obrera en Chile: confrontación comunista-socialista y la división de la CTCH (1946-1947). Tesis para optar al grado de Magíster en Historia con mención en Historia de Chile. Universidad de Chile, Santiago, Noviembre de 2013. Bernardo Ibáñez presenta su versión detalladamente en su Memoria de la Confederación de Trabajadores de Chile, 1943-1946, Santiago, Imprenta el Progreso, 1946. También da cuenta de ello el texto de Barnard, op cit., 359

${ }^{67}$ Memorandum N66. 26 de enero de 1946, Sec. Sindical, Dirección General de Investigaciones, ARNAD, Min Int, vol 12004
} 
la cobertura periodística tendremos la impresión que se trató de un abrupto fracaso ya que tanto desde la derecha, el gobierno como el Partido Socialista se encargaron de imponer modelos de percepción y expresión desmovilizadores que resaltaban su fracaso. ${ }^{68}$

Pero si nos acercamos a los documentos y partes reservados de la Sección Sindical y Confidencial de la Policía de Investigaciones y del Ministerio del Interior inevitablemente matizaremos esta apreciación. Con todo, efectivamente nada prometedor podía resultar de una central obrera dividida, ello de por sí constituía una derrota a mediano plazo, por lo demás tampoco se avanzó mucho más -o nada- en los puntos que quedaban por resolver dentro del petitorio. No obstante, seguir los entretelones de este movimiento nos permite aproximarnos parcialmente tanto a la influencia del $\mathrm{PCCH}$ y las tendencias de izquierda (que incluyen a sectores socialistas que decidieron apoyar el paro) dentro del movimiento obrero, como las estrategias represivas del gobierno ${ }^{69}$.

Existe cierta coincidencia en señalar que en términos generales con Bernardo Araya se alinearon los gremios donde tenía hegemonía el $\mathrm{PCCH}$, es decir, la industria minera, metalúrgica, textil y construcción; por su parte con Ibáñez, lo hicieron los panificadores, molineros, beneficencia y química y farmacia, mientras que los ferroviarios, decidieron no tomar partido de la disputa. ${ }^{70}$ El cuadro se complejiza en cuanto dentro de algunos de los sectores socialistas se impugnaba la decisión del Comité Central. Como fue el caso de los empleados de CHILECTRA, que hicieron manifiesta su desaprobación en una declaración pública:

La Brigada Socialista de empleados de la Compañía Chilena de Electricidad, frente a la posición claudicante de los representantes del trotskismo en el Comité Central, que han acordado, al margen de las bases, cooperar en un Gabinete que no representa el sentir de los trabajadores, acuerda:

1.- Solidarizar ampliamente con la posición de la CTCH y adherir al paro general indefinido.

2.- Protestar por el atropello que se ha hecho a las bases del Partido, al tomar resoluciones que no interpretan el sentir de la militancia.

\footnotetext{
${ }^{68}$ Ver por eje, el seguimiento de los diarios La Opinión, La Nación, El Diario Ilustrado y El Mercurio.

${ }^{69}$ La hegemonía comunista entre los obreros del carbón ha sido trabajada y demostrada por Pavilack, op cit

70 Jorge Barría, Trayectoria y estructura del Movimiento Sindical Chileno. 1946-1962. Santiago. Inst. de Organización y Administratión INSORA, Fac. de Ciencias Económicas, 1963. Tal como apunta Pozo, op cit, según El Siglo, a inicios de marzo la mayoría de las federaciones y 18 consejos provinciales ratificaron la expulsión de Ibáñez, reconociendo a Bernardo Araya como Secretario de la CTCH. Entre estas: Construcción, Metalúrgica, Minera, del Cuero, Cervecera, Pasteleros, Textiles, Choferes de Taxis, Trabajadores Agrícolas, Electricidad, Gas y Teléfonos, Portuarios y Marítimos, Comerciantes Ambulantes, Pescadores y Molineros. El Siglo, 3 de marzo de 1946
} 
3.- Denunciar al fascista Rossetti, como traidor a la clase trabajadora, al pretender entregar al Partido a la reacción, hundiéndolo en el lodo de sus nefastos propósitos. ${ }^{71}$

Desde el 2 de febrero se supo que en Valparaíso obreros de los muelles, diversas industrias textiles y obras de construcción habían detenido sus labores. Según fuentes periodísticas, algunos de ellos, como gran parte de la gente de mar regresó a trabajar después del quiebre de la CTCH. Las Maestranzas de San Eugenio y San Bernardo de ferrocarriles se plegaron en la mañana del día 2 y continuaron en paro hasta el día 8, lo mismo hicieron los obreros de la Cía. de Gas de Santiago, que fue tomada por el ejército ${ }^{72}$. Para el día 4 se sumaron 235 obreros de la Fábrica de Papel ubicada en Santa Elena esquina Acacios, además de 33 obreros que tenían a su cargo el control de las torres de alta tensión de la Cía Chilena de Electricidad. ${ }^{73}$ Como vemos en la tabla $\mathrm{N}^{\circ} 1$, las principales actividades de la provincia de Santiago que involucraban a los gremios organizados se encontraban paralizados en un $58 \%$ aprox. En tanto el comercio minorista, bancos, cajas, empleados particulares y prendarios se encontraban trabajando normalmente. En cuanto a los telefonistas, éstos se suman dos días más tarde por lo que no están contabilizados en la tabla.

\begin{tabular}{|l|c|c|c|}
\hline \multicolumn{4}{|c|}{ Diversos gremios obreros paralizados en Santiago 4 de febrero 1946 } \\
\hline & Total de obreros & Trabajan & En Huelga \\
\hline Panificadores & 5.000 & 2.000 & 3.000 \\
\hline Calzado y Cuero & 14.000 & 8.400 & 5.600 \\
\hline Ferroviarios & 22.000 total país & 5.000 total país & 17.000 \\
\hline Textiles & 10.400 & 7.000 & 3.400 \\
\hline Alcantarillado & 700 & 400 & 300 \\
\hline Metalúrgicos & 12.000 & 3.000 & 9.000 \\
\hline Cerveceros & 1.400 & 200 & 1.200 \\
\hline Madera y muebles & 9.000 & 2.700 & 6.300 \\
\hline Molineros & 1.000 & 500 & 500 \\
\hline Taxis & 2.200 & 1.800 & 400 \\
\hline Matarifes & 1.000 & 1.000 & 0 \\
\hline Construcción & 9.000 & 2.000 & 7.000 \\
\hline Gas & 850 & 0 & 850 \\
\hline Obreros de imprentas & 3.470 & 550 & 2.920 \\
\hline Electricidad & 2.250 & 1.000 & 1.250 \\
\hline Agua potable & 700 & 400 & 300 \\
\hline
\end{tabular}

${ }^{71}$ El Siglo, 3 de febrero de 1946.p.8

${ }_{72}^{72}$ Las noticias de última hora, 3 de febrero de 1946

${ }^{73}$ Las noticias de última hora, 4 de febrero de 1946

${ }^{74}$ Elaboración propia con datos obtenidos de Memorandum Nª9, 4 de febrero 1946, Sec. Sindical, Dirección General de Investigaciones, ARNAD, Min Int, vol 12004. Se refiere a las principales actividades de la provincia y se considera en ella a los gremios organizados. 


\begin{tabular}{|l|c|c|c|}
\hline Beneficencia & 6.000 & 5.400 & 600 \\
\hline Choferes y cobradores & 3.500 & 2.100 & 1.400 \\
\hline Tranviarios & 1.540 & 1.200 & 340 \\
\hline Municipales & 2.200 & 1.500 & 700 \\
\hline Pavimentación & 400 & 200 & 200 \\
\hline Teléfonos (*) & 200 & 200 & 0 \\
\hline Vidrieros (**) & 1.400 & 100 & 1.300 \\
\hline \hline TOTAL & $\mathbf{1 1 0 . 2 1 0}$ & $\mathbf{4 6 . 6 5 0}$ & $\mathbf{6 3 . 5 6 0}$ \\
\hline
\end{tabular}

(*) El 6 de febrero se sumaron los obreros de la Cía. de Teléfonos de Chile ${ }^{75}$

(**) Datos del Memorandum $N^{\circ} 123,8$ de febrero de 1946. Sección Sindical. Dirección General de Investigaciones.

Mientras la protesta obrera se desarrollaba, continuaron los arrestos que a esa altura ya sumaban más de 500 detenidos a lo largo del país, acusados de infringir las disposiciones de la Ley de Seguridad del Estado. Solo en Santiago el 5 de febrero hubo 40 detenidos por impedir la libertad de trabajo ${ }^{76}$ y otros 30 al día siguiente, capturados en las inmediaciones del local del Sindicato de la Compañía de Teléfonos "promoviendo e incitando, además, a otros obreros de la Compañía a declararse en huelga",77. También fue detenido Luis Coll Oyanza de 28 años, por incitar a la huelga a 100 obreros de la Fábrica de pasteles y confites de Juan de Frutos. ${ }^{78}$ La misma suerte corrió el carpintero Luis Humberto Olivares de 37 años de edad, sorprendido y detenido en la intersección de Av. Matta oriente con San Eugenio "repartiendo panfletos del Partido Comunista, incitando a la vez a los obreros y al pueblo a apoyar la huelga ilegal acordada por la CTCH". Se trataba de discursos pronunciados en el Senado de la República el sábado 2 de febrero por Carlos Contreras Labarca, Secretario General del PCCH y Gabriel González Videla dirigente del Partido Radical. ${ }^{79}$ El panfleto titulaba "Triunvirato militar gobierna al país. El fascismo internacional concentra sus fuegos en Chile". En algunos puntos de la ciudad fueron apedreados algunos autobuses y microbuses que transitaban por Vergara Montt cerca de la Fábrica Yarur, en la población San Eugenio y en el camino a San Bernardo resultando ocho detenidos. Hubo seis detenidos en Vitacura $\mathrm{N}^{\circ} 185$ acusados de intentar impedir el ingreso a trabajadores y un detenido en Alameda con Nataniel por inutilizar un tranvía. ${ }^{80}$ La acción

\footnotetext{
${ }^{75}$ Memorandum N¹15, 6 de febrero de 1946 Sec. Sindical, Dirección General de Investigaciones, ARNAD, Min Int, vol 12004

${ }^{76}$ Oficio $\mathrm{N}^{\circ} 98$, Detenidos por impedir la libertad de trabajo. 7 de febrero de 1946, Dirección General de Carabineros, ARNAD, Min Int, vol 12004

${ }^{77}$ Detenidos por infracción a la Ley de Seguridad Interior del Estado N6026. Santiago 6 de febrero 1946, ARNAD, Min Int, vol 12004

${ }^{78}$ Las noticias de última hora, 4 de febrero de 1946

${ }^{79}$ Oficio $\mathrm{N}^{\circ} 1242$, Sobre detención de individuo por incitar a huelga ilegal, 6 de febrero 1946. Dirección General de Carabineros de Chile al Ministerio del Interior. ARNAD, Min Int, vol 12004

${ }^{80}$ Las Noticias de última hora, 4 de febrero de 1946
} 
de Carlos Sarmiento Silva, de 24 años, fue reivindicada días más tarde por las Juventudes Comunistas en el periódico Mundo Nuevo:

El compañero Sarmiento había introducido un pedazo de fierro en el motor del tranvía 413 de la línea 24 Macul, con lo que logró inutilizar el vehículo y detuvo el tránsito que venía de la Estación Central, durante cerca de media hora. Este es un ejemplo de cómo la juventud participa activa y combativamente en el Gran Paro Nacional de lucha por nuestra democracia. $^{81}$

También en O’Higgins donde estaba completamente paralizado Sewell, Mina y Coya, el molino San Pedro y Planta El Sauzal se registraba una veintena de detenidos acusados de impedir la libertad de trabajo. Ante la fuerte represión los obreros de Sewell decidieron protestar por telegrama al Ministro del Interior:

Ante provocaciones y detenciones de obreros y mujeres por carabineros pedimos U.S amparo para nuestros sindicatos. Hay indignación en campamento ante arbitrarias medidas. Rogamos U.S instruir jefe de plaza el cese de estos actos. Protestamos ante falsas informaciones radiocomunicaciones gobierno. Paro mantendremos indefinido cumpliendo órdenes gloriosa confederación de trabajadores de chile. González presidente. Pardo secretario sindicato. ${ }^{82}$

En el norte del país durante la mañana del 4 de febrero sólo trabajaban 466 obreros en Chuquicamata. ${ }^{83}$ En Chañaral los obreros de la Andes Copper acordaron sumarse al paro, en tanto en Tocopilla se plegaban los matarifes y panificadores, las oficinas María Elena y Pedro de Valdivia. En Calama paraban los obreros del Gas, Molineros, Fábrica de Sacos, Compañía de explosivos de Calama, personal de Municipalidad de Calama, FFCC de Antofagasta a Bolivia ${ }^{84}$. Como observamos en la tabla $\mathrm{N}^{\circ} 2$ en Iquique el $72 \%$ de trabajadores se plegaba.

\footnotetext{
${ }^{81}$ Mundo Nuevo, febrero de 1946, portada.

${ }^{82}$ Telegrama dirigido al Min. del Interior, Sewell 5 de febrero de 1946, ARNAD, Min Int, vol 12004

${ }^{83}$ Comunicaciones del país relacionadas con el paro. Subsecretario Ministerio del Interior, 4 de febrero de 1946, ARNAD, Min Int, vol 12004

${ }^{84}$ Las noticias de última hora, 5 de febrero de 1946
} 


\begin{tabular}{|c|c|c|c|}
\hline \multicolumn{4}{|c|}{ Resumen Paro en Iquique 5 de febrero $1946^{85}$} \\
\hline & $\begin{array}{l}\text { Total de } \\
\text { obreros }\end{array}$ & Trabajan & En Huelga \\
\hline Jornalero y estibadores & 193 & 13 & 180 \\
\hline Costuras y achicadores & 110 & 69 & 41 \\
\hline Lancheros & 28 & 0 & 28 \\
\hline Cargadores marítimos & 97 & 0 & 97 \\
\hline Fleteros & 63 & 0 & 63 \\
\hline Carpinteros y calafates & 26 & 0 & 26 \\
\hline Obras Portuarias & 115 & 0 & 115 \\
\hline Choferes & 65 & 0 & 65 \\
\hline FF.CC. de Iquique a Pintados & 229 & 0 & 229 \\
\hline FF.CC Salitrero & 402 & 0 & 402 \\
\hline Alumbrado & 76 & 20 & 56 \\
\hline Fundición Wacholtz & 26 & 0 & 26 \\
\hline Cavancha & 130 & 0 & 130 \\
\hline Oficina Santa Rosa de Huara & 400 & 95 & 305 \\
\hline Oficina Mapocho y Camp Santiago & 1.391 & 123 & 1.268 \\
\hline Oficina Humbrestone & 775 & 175 & 600 \\
\hline Oficina Santa Laura & 158 & 28 & 130 \\
\hline Oficina Peña Chica & 218 & 171 & 47 \\
\hline Oficina Querima & 153 & 25 & 128 \\
\hline Campamento San José & 427 & 21 & 406 \\
\hline Campamento Cala-Cala & 472 & 20 & 452 \\
\hline Campamento Don Guillermo & 379 & 28 & 351 \\
\hline Oficina Victoria & 1615 & 586 & 1.029 \\
\hline Oficina Alianza & 190 & 30 & 160 \\
\hline Oficina Bellavista & 55 & 12 & 43 \\
\hline Oficina Pan de Azúcar & 750 & 85 & 665 \\
\hline Oficina Diez de Septiembre & 650 & 130 & 520 \\
\hline Oficina Iris (*) & 665 & 0 & 665 \\
\hline Camiña & 351 & 0 & 351 \\
\hline Oficina Aguada & 340 & 340 & 0 \\
\hline Oficina Gloria y Camp. Santa Ana & 466 & 466 & 0 \\
\hline Agua Potable & 100 & 100 & 0 \\
\hline Alumbrado & 109 & 109 & 0 \\
\hline Panificadores & 130 & 130 & 0 \\
\hline Municipales & 200 & 200 & 0 \\
\hline Beneficencia & 246 & 246 & 0 \\
\hline Caja crédito & 100 & 100 & 0 \\
\hline bancarios & 45 & 45 & 0 \\
\hline TOTAL & 11.945 & 3.367 & 8.578 \\
\hline
\end{tabular}

(*) Al día siguiente se reintegraron 150 mineros

\footnotetext{
${ }^{85}$ Elaboración propia con datos del Memorandum N ${ }^{\circ} 169,5$ de febrero 1946, Sec. Sindical, Dirección General de Investigaciones, ARNAD, Min Int, vol 12004
} 
Junto a la pampa, la zona minera e industrias anexas en Lota, Schwager, Coronel y Tomé se encontraban paralizados desde el día 2 y proseguirán la huelga hasta mediados de febrero. A los obreros textiles, de la compañía de gas, de la construcción y otras industrias menores, se sumaban los de la planta eléctrica que estaba operando al mínimo para mantener el servicio, los ferrocarrileros, los obreros de la Fábrica Chiguayante (de los 2.200 acudieron sólo 250), la Fábrica El Tigre trabajaba al $50 \%$ y en la fábrica de vidrios planos de Lirquén solo un pequeño número había acudido. Además, estaban totalmente paralizados los de Fanaloza, vidrios Schiavi, los cerveceros, obreros portuarios y tripulaciones. De hecho, el vapor argentino Río Neuquén que arribó al puerto de Coronel tuvo una importante complicación al encontrarse varado por no poder obtener carboncillo para la carga ni carbón para combustible.

Era costumbre que tras cada día de huelga los trabajadores se reuniesen para evaluar la situación tanto en sus locales como en plazas públicas. Gracias a su red de espías, los informes de la Sección Sindical de la Policía de Investigaciones instalados puntualmente en ellos, nos dan pistas sobre el estado de opinión y ánimo de los obreros. Lo que observaremos recurrentemente en este caso serán los constantes ataques al gabinete socialista-militar, las protestas contra la masacre de la Plaza Bulnes y el abandono de los heridos y familiares de las víctimas, junto a las pugnas que se dirimían entre comunistas y socialistas.

Por ejemplo, sabemos que el 7 de febrero los trabajadores de Concepción se reunieron para evaluar las propuestas de la Dirección Nacional de la CTCH. Al caer la tarde alrededor de siete mil personas llegaron hasta la Sala Gimnasio del sindicato de la Fábrica de Paños Concepción. Los líderes gremiales y sindicales fueron tomando la palabra y confirmando su presencia en el movimiento, así lo hizo el sindicato de la Compañía de gas y los obreros ferroviarios, que aprovecharon de acusar la traición de los compañeros de rieles de la Santiago Watt que se bajaron del paro. No obstante, las más fuertes rencillas se manifestaron cuando tomó la palabra el representante de la Federación Minera, Luis Varela Gaete para defender a Bernardo Ibáñez argumentando que su postura había sido tergiversada por la prensa reaccionaria y amarilla, "por lo que no debía haberse estimado como ruptura del movimiento huelguístico". Señala el memorándum: "Los asistentes contrarios a las ideas del orador, no le permitieron continuar el discurso, haciéndose presente en la concentración una verdadera batalla de improperios y contramanifestaciones que no llegaron a las vías de hecho.- Después de treinta minutos volvió la calma al local social." ${ }^{, 86}$ En tanto en el comicio realizado en Lota, al igual que en otros puntos del país, los oradores impugnaban el gabinete señalando "no representaba las aspiraciones ni las

\footnotetext{
${ }^{86}$ Memorandum Reservado N9. 7 de febrero de 1946, Sección Confidencial, Dirección General de Investigaciones, ARNAD, Min Int, vol 12004
} 
necesidades del proletariado chileno, y que en cuanto a los militares en el Gabinete ello constituía un insulto para la civilidad y para las fuerzas democráticas del país."87

El Jefe de Zona en Concepción y Arauco, que sería Ministro del Interior durante el régimen de González Videla, Contraalmirante Holger Torres comandó una fuerte represión. Los dirigentes obreros de Fanaloza Penco en Concepción fueron desalojados por la fuerza pública del local sindical, detenidos y puestos a disposición de la corte de apelaciones algunos de ellos por incitar a la huelga. Se les acusaba de intentar agredir al nuevo personal contratado por la fábrica: "Los asaltantes concurrieron armados de laques por lo que el personal de Carabineros y del Ejército procedió a disolverlos". La vigilancia del pequeño radio del sindicato fue reforzada con 20 militares. ${ }^{88}$ Además, a las 23:30 hrs al terminar la asamblea en el local del sindicato de la Fábrica de Paños de Concepción, tropas de carabineros detuvieron a huelguistas en los alrededores, "los que participaban en la reunión, al tener conocimiento de este hecho, salieron a la calle y pretendieron arrebatar a Carabineros los detenidos. Carabineros se vio en la necesidad de repeler el ataque disparando al aire y disolviendo a los asambleístas". 89

En tanto en Santiago, El Siglo publicaba varias denuncias, como golpes y persecuciones a sus repartidores, la situación de 100 ferroviarios detenidos, el hostigamiento en fábricas a trabajadores, cancelación de contratos, detenciones de obreros en sus domicilios e incluso aplicación de torturas. Destacando además el ingreso de la fuerza pública al local del Sindicato Industrial de la Cía. de Teléfonos de Chile resultando más de 20 detenidos. ${ }^{90}$

A pesar que la facción comunista era mayoritaria el gobierno le otorgó reconocimiento solo a los socialistas. Esto lo confirmó dirigiendo a Bernardo Ibáñez la respuesta a los 12 puntos que estaba esperando la $\mathrm{CTCH}$. En ella se detiene en cada punto pero no aporta nada en concreto. Sobre el amplio arco de materias planteadas para los fines de este texto nos interesa resaltar algunos de ellas. Por ejemplo sobre el punto 1 y 3 dedicado a exigir la derogación del estado de sitio y rehabilitación de la personalidad jurídica, el ejecutivo se remite a los decretos ya emitidos. En el punto 2, que abordaba la constitución de un gobierno civil de izquierda que dé solución a los problemas del pueblo, garantice el castigo ejemplar para los culpables de los sucesos de la Plaza Bulnes, el ejecutivo se reserva la facultad privativa que le otorga la Constitución al Presidente de la República para su designación. Y advertía:

\footnotetext{
${ }^{87}$ Memorandum $N^{\circ} 114,5$ de febrero de 194, Sec. Sindical, Dirección General de Investigaciones, ARNAD, Min Int, vol 12004

88 Radiograma de Carabineros de Chile, 7 de febrero de 1946; y Memorandum №121, 7 de febrero de 1946. Sec. Sindical, Dirección General de Investigaciones, ARNAD, Min Int, vol 12004

${ }^{89}$ Memorandum N ${ }^{\circ} 121,7$ de febrero de 1946, Sec. Sindical, Dirección General de Investigaciones, ARNAD, Min Int, vol 12004

${ }^{90}$ El Siglo, 8 de febrero 1946
} 
En estos momentos no se alterará la constitución del ministerio debido a la indisciplina y a la incomprensión demostrada por una parte de la masa obrera. La Justicia Militar conoce del proceso por los hechos ocurridos en la Plaza Bulnes y solamente a ella le corresponde determinar las responsabilidades en esos sucesos y el castigo de los que resulten culpables

En cuanto a la indemnización de la familia de las víctimas (punto 4), respondía: "Esta indemnización sólo puede ser materia de una ley. El Gobierno apoyará el proyecto una vez que se conozca el resultado del sumario". Sobre la Derogación de la Ley de Emergencia y retiro inmediato de las Fuerzas Armadas en la intervención de los conflictos de trabajo (punto 6), indicaba: "Es obligación primordial del Gobierno mantener el orden público y la tranquilidad social. Asimismo debe asegurar la libertad de trabajo, y, lógicamente, debe usar de los medios que la ley le otorga"

Sobre la función arbitral que se le reclamaba al gobierno en los conflictos del trabajo como aplicar drásticas medidas contra los abusos patronales -no cumplir convenios, fallos arbitrales, despidos arbitrarios e incumplimiento del reglamento de seguridad industrial- (punto 7) y en especial frente a la COSATAN por las demandas que mantenía vigentes contra los sindicatos (punto 8), el gobierno respondía con la evasiva promesa de estudiar modificaciones al Código del Trabajo y solicitar la suspensión de los juicios a las empresas con la condición previa del regreso al trabajo. ${ }^{91}$

Ante el aplomo de estas respuestas y quedándose sin mucho margen de maniobra al día siguiente la CTCH dio por terminado el paro. Sin haber avanzado en la consecución de sus demandas, los trabajadores se fueron reintegrando paulatinamente a las faenas a excepción de algunas industrias y centros mineros que continuaron la huelga debido a represalias patronales como despidos, contratación de personal nuevo e incluso impidiendo la entrada a los obreros por el resto de los días de la semana a fin de no pagar la semana completa. Para el día 11 de febrero continuaba paralizada la zona del carbón y estaban decididos a no terminar hasta que se resolviese el conflicto de más de 300 obreros desahuciados. En Santiago, continuaba el conflicto en Cristalerías de Chile y en la Fundición Libertad debido a la renovación total de los contratos. La Maestranza de Agua Potable estaba completamente paralizada y en la Cía. de Gas solo habían regresado a sus labores 52 hombres. En La Calera, sólo trabajaban 30 de 200 obreros de Cemento Melón y Mina Calera sólo contaba con $80 .^{92}$

\footnotetext{
${ }^{91}$ Nota de prensa dirigida a Sr. Bernardo Ibáñez, secretario General de la Confederación de Trabajadores de Chile, firmada por Manuel Aguirre Geisse, Secretario General de Gobierno, 7 de febrero de 1946. ARNAD, Min Int, vol 12004

${ }_{92}$ Memorandum $N^{\circ} 137.11$ de febrero de 1946 Sec. Sindical, Dirección General de Investigaciones, ARNAD, Min Int, vol 12004
} 
En la mañana del 10 de febrero se realizaron dos importantes encuentros. La fracción de Araya convocó en la Plaza Ercilla, espacio que había utilizado en las últimas concentraciones la CTCH dado la negativa de la Intendencia para volver a utilizar la Plaza Bulnes. La manifestación comenzó con complicaciones ya que fue cortada la energía eléctrica que impidió la utilización de altoparlantes lo que provocó protestas entre los concurrentes. Según el parte de la Sección Sindical, "uno de los asistentes a ella, quemó un mono que representaba al líder obrero Bernardo Ibáñez, mono que exhibía un letrero que decía ¡EL TRAIDOR IBÁÑEZ...!"93. En tanto los enviados de la Sección Confidencial resumían en su informe:

El señor Bernardo Araya expresó en primer término que protestaba enérgicamente porque una vez más se impedía que la clase obrera escuchara a sus dirigentes, al cortar la corriente eléctrica, mientras que a los tránsfugas del movimiento obrero se les permite dirigir en cadena a todo el país.

El reclamo de Araya no era gratuito ya que desde las 11:30 se transmitió por radio Cooperativa Vitalicia, en cadena con otras emisoras, los pormenores y discursos de la concentración del PS en el teatro Caupolicán. Durante varios minutos el propio Ibáñez se tomó el tiempo necesario para justificar su postura ante los últimos hechos: "Nunca les he dicho "retrocedan"; nunca he frenado un movimiento obrero; dicen que los he traicionado; voy a explicarlo", entonces argumentó que tal como lo había expresado ante el Consejo si bien no estaba de acuerdo en realizar una huelga y menos aún indefinida, la había apoyado para mantener la unidad sindical; no obstante después tuvo que recapitular dadas las circunstancias, pero no sin antes notificarlo a sus compañeros:

El Partido socialista fue llamado a las tareas del gobierno para evitar una profunda guerra civil que se desencadenaba. El panorama había cambiado y así lo hice ver ese domingo al Comité de Huelga.- El PS ha acordado ir al gobierno y nuestros Ministros jurarán en momentos más.- por lo tanto, yo tendré que lanzar un Manifiesto al país en que me opongo al paro.

Ibáñez no dejó pasar la oportunidad para expresar públicamente su reconocimiento al "Gobierno y los Institutos armados de la Nación, éstos últimos que son la reserva moral de Chile". ${ }^{94}$ Lo mismo harían los cuerpos armados en el gabinete al considerar prácticamente

\footnotetext{
${ }^{93}$ Memorandum $N^{\circ} 136.10$ de febrero de 1946 Sec. Sindical, Dirección General de Investigaciones, ARNAD, Min Int, vol 12004

${ }^{94}$ Memorándum reservado $\mathrm{N}^{\circ} 10,10$ de febrero de 1946. Sección Confidencial, Dirección General de Investigaciones, ARNAD, Min Int, vol 12004. Ver además. Ibáñez, op cit
} 
controlado el conflicto obrero. Así el 14 febrero, el Ministro del Interior Merino Bielich felicitó públicamente al Director General de Carabineros General Eduardo Maldonado:

Con ocasión del último conflicto obrero, generalizado en todo el país, el Gobierno de la República ha podido comprobar el eficiente desempeño del Cuerpo de Carabineros en el mantenimiento del orden público y resguardo de la libertad de trabajo (...) haciendo honor a sus tradiciones, ha sabido comportarse con el patriotismo y sacrificio requeridos por la gravedad de los acontecimientos que viviera la nación. ${ }^{95}$

Casi un año después de los hechos de la Plaza Bulnes el sumario no arrojaba respuestas. ${ }^{96}$ Nadie fue castigado por la matanza. Ni los familiares de las víctimas recibirían ayuda por parte del estado, ni tampoco los heridos que terminaron imposibilitados de trabajar debido a la secuela de las heridas por balas (la gran mayoría alojadas en manos, brazos y piernas). Entonces ya corría enero de 1947 y el discurso anticomunista fervorosamente utilizado para legitimar la represión y las políticas anti-obreras en los años precedentes operaba en un poderoso caldo de cultivo, insospechado para la gran mayoría.

\section{Conclusiones}

Sistemáticamente observamos que las estrategias dominantes tienden a aislar las luchas, las organizaciones, los procesos, de manera que desaparezca el grupo y quede la percepción de estar ante una sumatoria de individuos o una excepcionalidad de sucesos sin complicidad ni conexión entre ellas. ${ }^{97}$ Esta consideración inspiró uno de los objetivos de esta investigación que creemos haber demostrado, el encadenamiento de luchas obreras suscitadas en este período y su impacto en el sistema político. En éstas la dirección política sindical se reveló indispensable como eje articulador, orientador y movilizador del que dependía la demostración unitaria de fuerza y así quedó demostrado tanto en el exitoso paro del 30 de enero como en las magras consecuencias que tendría la división orgánica de la CTCH a corto y mediano plazo.

En efecto, en los sucesos vividos durante el verano de 1946 los obreros lograron reconocerse a sí mismos como parte de un todo, no sólo directamente en función de sus propios intereses, sino para disputar y defender a nivel nacional su posición dentro del territorio de lucha social en que se desplegaba la configuración de un nuevo ciclo represivo.

${ }^{95}$ El Diario Ilustrado, 15 de febrero de 1946, portada

${ }^{96}$ Ver el dictamen del fiscal, fallos de primera y segunda instancia y sobreseimiento temporal del 28 de diciembre de 1946 presentados ante la Corte Marcial. En "Dictamen del fiscal". Causa 80-1946, ARNAD, Min. Int, vol 12386

${ }^{97}$ Bourdieu, op. cit., p198 
La protesta ante la supresión de la personalidad jurídica que afectó a dos sindicatos y la matanza de la Plaza Bulnes fueron experimentados como un violento atentado contra un "nosotros", en tanto ambos significaban la muerte física y simbólica de lo que ellos representaban. De ahí la solidaridad que movilizó al país en el paro nacional del 30 de enero. El problema de uno era el de todos, y ese sentido unificador de la experiencia de clase era lo que tenían en común una joven obrera de los laboratorios Recalcine en Santiago, como Ramona Parra Alarcón, con Miguel Astorga Astorga, calderero de la oficina Ramírez en Tarapacá.

No era fácil para un obrero u obrera caminar aquellos días en los lugares cercanos a sus sindicatos, menos aún leer sus publicaciones en la vía púbica o debatir despreocupadamente en una esquina. La fuerza policial los custodiaba permanentemente, muchos locales eran allanados y clausurados, a los desfiles y comicios planeados se les restringía o negaba el espacio público, se encarcelaba a los sospechosos de incitar a los desmovilizados, se censuraba y requisaba la prensa. Asesinatos o despidos, golpes e interrogatorios nos invitaron a cuestionar un proceso ascendente de democratización social y neutralización de las confrontaciones supuestamente interrumpido con la Ley Maldita.

Con todo, la izquierda movilizada de la que hemos dado cuenta continuaba aumentando sus fuerzas y esto lo podemos observar en los procesos eleccionarios. Meses más tarde de las protestas obreras que aquí reconstruimos el hasta entonces radical progresista González Videla ganaba las elecciones gracias al apoyo del PCCH. En esa oportunidad también se presentaba como contendor Bernardo Ibáñez, logrando tan solo el $2.53 \%$ de los votos. Mientras el socialismo seguía bajando en las urnas, las municipales de abril de 1947 volvían a poner en alerta a los sectores dominantes. El PCCH triplicaba su votación (de 32 mil votos obtenidos en 1944 a 91 mil). El obtener el 16.5\% de los votos le permitió elegir a 13 alcaldes y 187 regidores. Además de porcentajes por sobre el $50 \%$ en zonas conflictivas de movilización social $(55 \%$ en el cobre, $63 \%$ salitre, $71 \%$ en el carbón). ${ }^{98}$ Pero la fuerza demostrada a nivel electoral no sería suficiente para responder ni táctica ni estratégicamente el golpe que vendría.

No fueron pocos los que sacaron cuentas: esa votación en las parlamentarias de 1949 le permitiría al PCCH ser el principal grupo parlamentario con 30 escaños. Diez días más tarde de las elecciones municipales comenzaba con fuerza la cruzada en contra del comunismo. Insistiendo en que el González Videla no operó -no pudo operar- solo, sino que fue parte de una corriente ya presente en el sistema político chileno, diversos actores pactaron un propósito al que se entregarían con ahínco: utilizar la fuerza represiva del estado para disciplinar al movimiento obrero e imponer el orden social. Las consecuencias recorrerían todo el siglo.

\footnotetext{
${ }^{98}$ Huneeus, op cit, pp109-112
} 


\section{Bibliografía}

- $\quad$ Agulhon, Maurice. El círculo burgués. Siglo XXI, 2009

- Araya, Bernardo. "Una CTCH Unida. Combatiendo en defensa de la clase obrera y el pueblo", II Conferencia Nacional de la Confederación de Trabajadores de Chile. Santiago, 1946

- Arrate, Jorge; Eduardo Rojas, Memoria de la izquierda chilena, Tomo I. Santiago, Javier Vergara Editor, 2003

- Barría Serón, Jorge. Trayectoria y estructura del Movimiento Sindical Chileno. 1946-1962. Santiago. Inst. de Organización y Administratión INSORA, Fac. de Ciencias Económicas, 1963

- Barnard, Andrew, The Chilean Communist Party: 1922-1947. Ph.D thesis, University of London, 1977

- Bourdieu, Pierre, “La Huelga y la acción política”, En: Sociología y Cultura., México, Grijalbo, 1990.

- Casals Araya, Marcelo, La creación de la amenaza roja. Del surgimiento del anticomunismo en Chile a la "campaña del terror" de 1964. Santiago, LOM, 2016

- Correa, Sofía. et. Historia del Siglo XX chileno, Santiago, Sudamericana, 2001

- De Ramón, Armando, Santiago de Chile. Historia de una sociedad urbana. Santiago, Catalonia, 2007

- Huneuus, Carlos, La Guerra Fría Chilena. Gabriel González Videla y La Ley Maldita. Santiago, Debate, 2009

- Ibáñez, Bernardo, Memoria de la Confederación de Trabajadores de Chile, 1943-1946, Santiago, Imprenta el Progreso, 1946

- Lobato, Mirta Zaida. La vida en las Fábricas: trabajo, protesta y política en una comunidad obrera, Berisso (1904-1970). Buenos Aires, Entrepasados/Prometeo Libros, 2001.

- Loveman, Brian y Elizabeth Lira, Poder judicial y conflictos políticos (Chile:1925-1958), Santiago, LOM, 2014

- Millas, Orlando, En tiempos del Frente Popular, I volumen, Santiago, Cesoc Ediciones, 1993

- Moulian, Tomás, Fracturas: de Pedro Aguirre Cerda a Salvador Allende (1938-1973), Santiago, LOM, 2006.

- Pavilack, Jody. Mining for the Nation. The Politics of Chile's Coal Communities from the Popular front to the Cold War. University Park: The Pennsylvania State University Press, 2011.

- $\quad$ Pizarro, Crisóstomo, La huelga obrera en Chile, Santiago, SUR, 1986

- Pozo Mayorga, Cristian: "Ocaso de la unidad obrera en Chile: confrontación comunistasocialista y la división de la CTCH (1946-1947). Tesis para optar al grado de Magíster en Historia con mención en Historia de Chile. Universidad de Chile, Santiago, Noviembre de 2013. 
- Salgado, Alfonso, "La familia de Ramona Parra en la Plaza Bulnes: Una aproximación de género a la militancia política, la protesta social y la violencia estatal en el Chile del siglo". Revista www.izquierdas.cl, número 18, IDEA-USACH, Santiago de Chile, abril 2014, pp. 128-145

- Thompson, E.P. Costumbres en común. Barcelona, Crítica, 1995

\section{$\underline{\text { Fuentes primarias }}$}

a) Documentos de Archivo

- Archivo Nacional de la Administración (ARNAD), Ministerio del Interior, Vol. 12004

- Sumario por sucesos ocurridos en la Plaza Bulnes, Causa rol No 80-1946, Segundo Juzgado Militar de Santiago

b) Periódicos

El Diario Ilustrado, Santiago, 1946

La Nación, Santiago, 1946

Las Noticias de Última Hora, Santiago, 1946

El Siglo, Santiago, 1946 